\title{
A Self-Tuning Proportional-Integral-Derivative-Based Temperature Control Method for Draw-Texturing-Yarn Machine
}

\author{
Rong Song ${ }^{1}$ and Shuting Chen ${ }^{2}$ \\ ${ }^{1}$ Wenzhou Vocational \& Technical College, Wenzhou 325035, China \\ ${ }^{2}$ Hangzhou Medical College, Hangzhou 310053, China \\ Correspondence should be addressed to Shuting Chen; shutinren@163.com
}

Received 1 October 2017; Accepted 12 November 2017; Published 6 December 2017

Academic Editor: Marco Spadini

Copyright (c) 2017 Rong Song and Shuting Chen. This is an open access article distributed under the Creative Commons Attribution License, which permits unrestricted use, distribution, and reproduction in any medium, provided the original work is properly cited.

\begin{abstract}
Owing to the fast time-varying characteristics, the temperature control for draw-texturing-yarn (DTY) machine has higher technical difficulties and results in challenges for system energy optimization. To address the matter, a self-tuning proportionalintegral-derivative- (ST-PID-) based temperature control method is proposed. Referring to the technical procedures of DTY machine, a thermodynamic model is set up. Then, a ST-PID minimum phase control system is constructed by the pole-point placement method. Subsequently, an artificial neural network based forgetting factor searching (ANN-FFS) algorithm is developed to optimize the system parameter identification. The numerical cases show that the proposed ANN-FFS algorithm can improve the parameter identification process, and the average identifying efficiency $(K>15)$ can increase by more than $50 \%$; compared with the fuzzy PID controller, the proposed ST-PID method can increase the control accuracy nearly 3 times for the static temperature ascending. The experimental results prove that the proposed ST-PID method has better abilities of characteristics tracing and antiinterference and can restrain the temperature fluctuation caused by objective switching and the factual control accuracy reaches 3 times that of fuzzy PID method.
\end{abstract}

\section{Introduction}

Draw-texturing-yarn (DTY) machine can induce tensile strain for long polyester fiber and make the fiber have higher elasticity. For the above operation, heating is an indispensable technical procedure, in which the temperature of heating cabinet is a key control objective. The control precision of temperature will influence the fiber quality parameters containing curl degree, coloration rate, and shrinkage ratio, and it should be limited to less than $\pm 2^{\circ} \mathrm{C}$ [1].

A DTY machine is of many production channels, in which the processing velocity is commonly higher than $500 \mathrm{~m} / \mathrm{min}$ [2]. Apparently, it is a classical fast time-varying control objective and brings forward challenges for temperature control systems. Moreover, the working temperature of DTY machine is prone to being influenced by peripheral environmental factors, such as fiber material, fiber moisture percentage, tensile speed, ambient temperature, and heating power. Therefore, the fast time-varying temperature control for DTY machine has higher technical difficulties.
Related research works suggested that proportionalintegral-derivative (PID) is an effective temperature control approach for different engineering areas. For the timevarying objectives, the digital PID algorithms with selfadapting abilities are developed to improve the control accuracy [3-7]. Attaran et al. put forward an energy efficiency optimization method for heating, ventilating, and air conditioning (HVAC) system by using a radial basis function neural network (RBFNN) combined with the epsilon constraint (EC). The method adopted the advanced algorithm of RBFNN for the HVAC system to estimate the residual errors, increased the control signal, and reduced the error results [8]. Trafczynski et al. proposed PID-controlled heat exchangers to analyze the influence of fouling on the dynamic behavior and proved that, at changed thermal resistance of fouling, the values of tuning parameters should be changed [9]. Moradi et al. developed a temperature controller for the linearized plant based on decoupled fuzzy PID and fuzzy PD-type methods. The results proved that the decoupled fuzzy PID 
controller could guarantee the robust performance against the model-based parametric uncertainties, and the poleplacement controller could lead to the less energy consumption [10]. Li et al. provided a GPC-PID-based control strategy for laminar cooling process, which could control the global temperature curve to produce high quality steel, and set up a TS fuzzy model to improve the temperature prediction accuracy [11]. Kanagalakshmi et al. proposed a multimodelbased PID controller for the real-time temperature control of injection molding machine to improve the operator setup time and product quality [12]. Zhang et al. presented a multiinput multioutput (MIMO) self-tuning temperature sensing and control system for efficiently modulating the temperature environment within a multimodule instrument, in which the internal temperature of the instrument converged to a target without the need of a system model, thus making the control robust [13]. Pamela and Godwin Premi presented a hot air temperature controller in oven for sterilization using fuzzy PID controller and adaptive smith predictor, which could maintain the optimum temperature in hot air ovens from a farther distance [14]. Zhang developed an improved PID controller based on predictive functional control (PFC) to test the chamber pressure in an industrial coke furnace. The experimental results showed that the controller had the better ensemble performance compared with traditional PID controllers [15].

From the above references, it can be inferred that the key matter of PID-based temperature control is tracing the characteristic variation of control objective and obtaining the accurate control parameters to guarantee the control effectiveness. For the fast time-varying characteristics of DTY machine channel (heating cabinet), the problems of dynamical parameter identification might become apparent. Consequently, to address the issue, we propose a self-tuning proportional-integral-derivative- (ST-PID-) based temperature control method for DTY machine.

To accomplish the above research target, the technical route is described as follows. (1) Referring to the thermodynamic characteristics of DTY machine heating cabinet, a discrete mathematics model is set up. (2) A ST-PID controller for DTY heating cabinet is designed, and the corresponding minimum phase control system is constructed by the polepoint placement method. (3) An artificial neural network based forgetting factor searching (ANN-FFS) algorithm is developed to improve the computation efficiency of system parameter identification. (4) A ST-PID controller is developed based on embedded system technologies, and the control effects are checked by the comparative experiments.

In general, the key scientific contribution of the paper is providing a ST-PID modeling method and a dynamical parameter identifying method for the fast time-varying temperature objectives. This research not only can offer theoretical references to the control system modeling-solving and energy conservation of fast time-varying process, but can supply direct technical evidences for control system development and energy optimization of related industrial applications.

This paper is organized as follows. In Section 2, the temperature control objective of DTY machine is described,

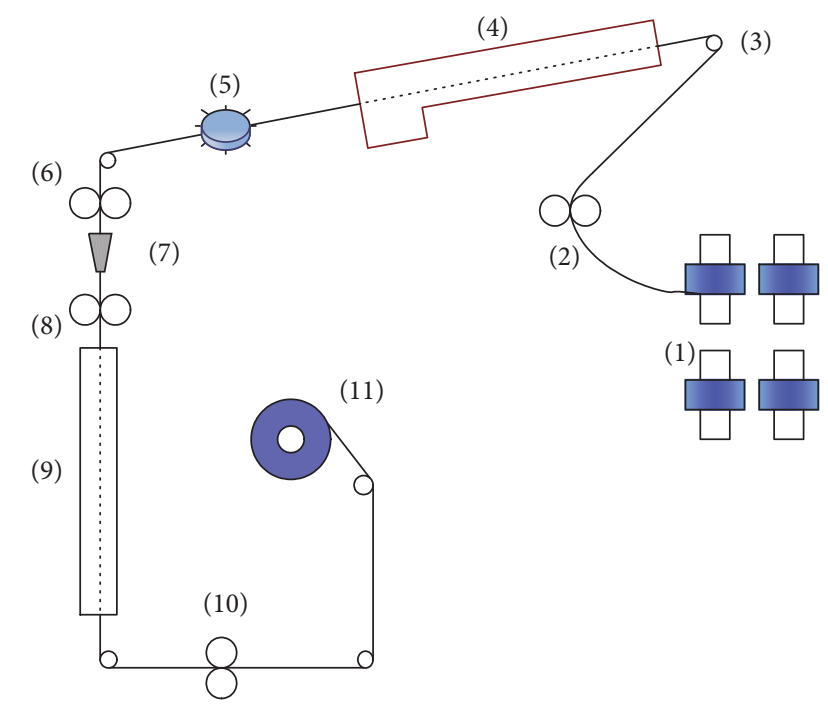

FIGURE 1: Working procedure of DTY machine: (1) raw fiber, (2) first roller, (3) stop twister, (4) heating cabinet, (5) false twister, (6) second roller, (7) nozzle, (8) third roller, (9) heating pipe, (10) fourth roller, and (11) fiber package.

and a thermodynamic model is set up. In Section 3, the digital PID-based temperature control method is presented, and the ST-PID controller for DTY machine is designed. In Section 4, the minimum phase system of ST-PID controller is constructed, and the ANN-FFS algorithm is proposed. In Section 5, the numerical instances are provided, and the results are discussed. In Section 6, a ST-PID controller is developed, and the comparative experiments are performed to verify the effectiveness of the proposed method. In Section 7 , the conclusions are presented.

\section{Control Objective and Thermodynamic Model}

The working procedure of DTY machine is shown in Figure 1. By the mechanical transmission structures, a bunch of fiber enters heating cabinet, where the tensile strain is induced by resistance heating and mechanical stretching. Then, the fiber passes through the heating pipe for shape setting and curls into a fiber package. With respect to the above operations, the fiber transmission process is of higher line velocity $(>500 \mathrm{~m} / \mathrm{min})$, so it is a classical fast time-varying objective.

Heating cabinet is the key control objective of DTY machine, as shown in Figure 2, and it contains three functional layers: constant temperature layer, heating layer, and thermal insulation layer. The resistance is activated and heats the atmosphere of the heating cabinet. Consequently, the temperature of heating cabinet increases, and the heat radiation of thermal insulation layer will rise. If the heating power equals the heat radiation rate, the temperature of heating cabinet tends to be stable.

For the heating cabinet, the physical conditions are as follows: the initial voltage and power of the resistance are $220 \mathrm{~V}$ and $5 \mathrm{~kW}$, respectively, the upper limit temperature 


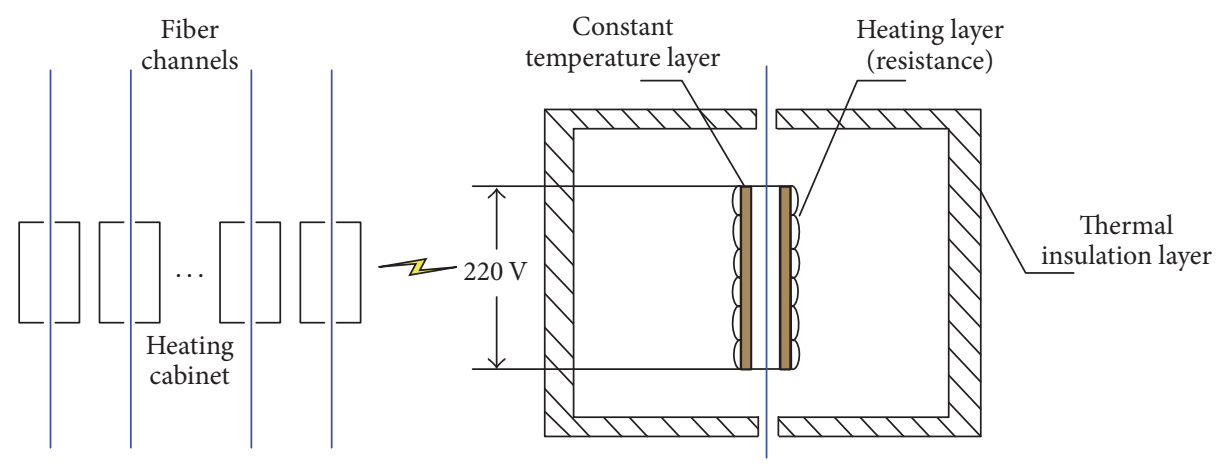

FIGURE 2: Structure of DTY machine heating cabinet.

is $200^{\circ} \mathrm{C}$, and the heating length is $1.5 \mathrm{~m}$. Consequently, we set up a thermodynamic model, as shown in Figure 3, where 1, 2, and 3 represent the air cell, insulation layer, and outside air, respectively; $T_{1}, T_{2}, T_{3}$ are the temperatures of air cell, insulation layer, and outside air; $C_{1}, C_{2}, C_{3}$ are the specific heats correspondingly; $Q$ is the input heat power; and $Q_{12}, Q_{23}$ are the thermal transmission quantities from air cell to insulating layer and insulating layer to outside air, respectively, [16-20].

Based on the above model, the following thermodynamic expression can be obtained:

$$
\begin{aligned}
Q-Q_{12} & =C_{1} m_{1} \frac{d T_{1}}{d t}, \\
Q_{12} & =K_{12} A_{1}\left(T_{1}-T_{2}\right), \\
Q_{12}-Q_{23} & =C_{2} m_{2} \frac{d T_{2}}{d t}, \\
Q_{23} & =K_{23} A_{2}\left(T_{2}-T_{3}\right),
\end{aligned}
$$

where $K_{12}, K_{23}$ represent the heat transfer coefficient, $m_{1}, m_{2}$ are the masses of air cell and insulating layer, and $A_{1}, A_{2}$ are the heat transfer areas. Since $C_{1} m_{1}, C_{2} m_{2}, K_{12} A_{1}, K_{23} A_{2}$ are constants, they are recorded as $c_{1}, c_{2}, k_{12}, k_{23}$ [21-24].

\section{Self-Tuning PID Temperature Control Method for DTY Machine}

3.1. Digital PID Control Method. Related research works suggested that temperature control can be described by the model of single-order inertia with lag annulus:

$$
G(s)=\frac{K}{\left(1+C_{d} s\right)(1+\tau s)}=\frac{K}{C_{d} \tau s^{2}+\left(C_{d}+\tau\right) s+1},
$$

where $K$ is the system gain factor, $\tau$ is the lag time, $C_{d}=$ $C / A_{r}$ is the time constant, $C$ is system specific heat, and $A_{r}$ is radiating coefficient $[3,4,25-27]$. Therefore, it will be with apparent variations according to the different control objectives and environmental conditions. Regarding the temperature objectives of industrial applications, the lag annulus is apt to arouse system overshoot and oscillation. Accordingly, the parameters of temperature objectives will be subjected

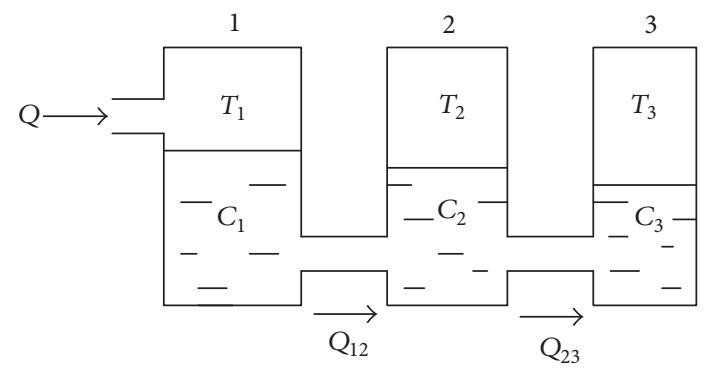

FIGURE 3: Thermodynamic model of DTY machine heating cabinet.

to large-scale changes. For example, during the course of electric furnace heating, since the cooler parts are placed into the furnace continuously, the temperature control model of electric furnace will be varied, and the high control accuracy is hard to achieve.

PID is a linear controller, which is one of the most widely used temperature control methods. Referring to the control effects of proportional-integral-derivative of output temperature error, it can be expressed as

$$
u(t)=K_{P}\left[e(t)+\frac{1}{T_{I}} \int_{0}^{t} e(t) d t+\frac{T_{D} d e(t)}{d t}\right],
$$

where $t$ is the time variable, $e(t)$ is the error between the ideal output $r(t)$ and factual output $y(t), K_{P}$ is the proportional constant, $T_{I}$ is integral time constant, and $T_{D}$ is derivative time constant. Related research works prove that PID can obtain better control effectiveness for some industrial applications and has two merits as follows. Firstly, it is of simple principle and structure and is easy to implement. Moreover, it can match the requirements of different industrial applications and is of higher robust performance [8-10, 28-31].

The current PID control methods can be divided into two modes: digital control and analogue control. The digital control method is prone to being realized by computer, and it has many technical advantages such as good flexibility, low cost, and reliable performance. The $Z$-transformation of incremental digital PID can be described as

$$
D(z)=\frac{U(z)}{E(z)}=K_{P}+K_{I} \frac{1}{1-z^{-1}}+K_{D}\left(1-z^{-1}\right) .
$$




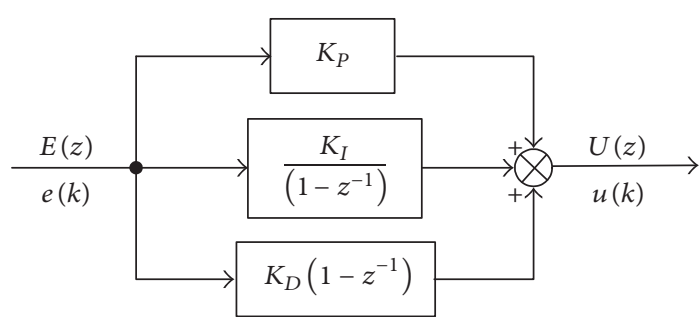

FIGURE 4: Schematic diagram of incremental digital PID controller.

As shown in Figure 4, the incremental digital PID controller only outputs the increment of control objective, that is, $\Delta u(k)$; then the following expression can be obtained:

$$
\begin{aligned}
\Delta u(k)= & K_{P} \Delta e(k)+K_{I} e(k) \\
& +K_{D}[\Delta e(k)-\Delta e(k-1)],
\end{aligned}
$$

where $\Delta e(k)=e(k)-e(k-1)$, and it contains the coefficients about sampling period, proportional ratio, integral time constant, and derivative constant.

\subsection{Self-Tuning PID Temperature Control Method for DTY} Machine. The self-tuning control is an effective method that can resolve the nonlinearities and time-varying objectives of complex systems, as shown in Figure 5.

Parameter tuning is the key matter of DTY machine temperature controller and can make the target system have an expected closed-loop characteristic equation. Regarding a linear time-varying objective,

$$
\begin{aligned}
A\left(z^{-1}\right) y(k) & =z^{-d} B\left(z^{-1}\right) u(k), \\
A\left(z^{-1}\right) & =1+\sum_{i=1}^{n_{a}} a_{i} z^{-i}, \\
B\left(z^{-1}\right) & =b_{0}+\sum_{i=1}^{n_{b}} b_{i} z^{-i} \quad\left(b_{0} \neq 0\right),
\end{aligned}
$$

where $b_{0}, a_{i}$, and $b_{i}$ are the system undetermined parameters. For the incremental digital PID controller, its $Z$-transform expression is

$$
G_{T}\left(z^{-1}\right)=\frac{g_{0} G^{\prime}\left(z^{-1}\right)}{1-z^{-1}}
$$

where

$$
\begin{aligned}
& G^{\prime}\left(z^{-1}\right)=1+\frac{g_{1}}{g_{0}} z^{-1}+\frac{g_{2}}{g_{0}} z^{-2}, \\
& g_{0}=K_{P}+\frac{K_{P} T}{T_{I}}+\frac{K_{P} T_{D}}{T}, g_{1}=-\left(K_{P}+\frac{2 K_{P} T_{D}}{T}\right), g_{2}=\frac{K_{P} T_{D}}{T},
\end{aligned}
$$

where $g_{0}, g_{1}$, and $g_{2}$ are the system control parameters. To guarantee the closed-loop stability, a filtering element needs to be introduced:

$$
F^{\prime}\left(z^{-1}\right)=1+f z^{-1}
$$

Accordingly, the system closed-loop control diagram is shown in Figure 6.

For the opened-loop stable minimum phase system, the pole-zero cancellation for the forward transform function is performed; that is,

$$
F^{\prime}\left(z^{-1}\right)=B^{\prime}\left(z^{-1}\right),
$$

where

$$
B^{\prime}\left(z^{-1}\right)=1+\frac{1}{b_{0}} \sum_{i=1}^{n_{b}} b_{i} z^{-1}
$$

With respect to some industrial applications, the model order can set $n_{a}=2$ and $n_{b}=1$, respectively. Subsequently, the pole points can be denoted by the control parameters $g_{0}$, $g_{1}$, and $g_{2}$, and let

$$
G^{\prime}\left(z^{-1}\right)=A\left(z^{-1}\right)
$$

then

$$
\begin{gathered}
\frac{g_{1}}{g_{0}}=a_{1}, \\
\frac{g_{2}}{g_{0}}=a_{2}, \\
f=\frac{b_{1}}{b_{0}} .
\end{gathered}
$$

The closed-loop transfer function can be expressed as

$$
\begin{aligned}
G\left(z^{-1}\right) & =\frac{b_{0} g_{0} z^{-d} /\left(1-z^{-1}\right)}{1+b_{0} g_{0} z^{-d} /\left(1-z^{-1}\right)} \\
& =\frac{b_{0} g_{0} z^{-d}}{1-z^{-1}+b_{0} g_{0} z^{-d}},
\end{aligned}
$$

where $b_{0}$ is a constant $\left(0<b_{0}<1\right)$. By the recursive least square (RLS) method, the control law of self-tuning controller is obtained as

$$
\begin{aligned}
u(k)= & u(k-1) \\
& +g_{0}\left[e(k)+a_{1} e(k-1)+a_{2} e(k-2)\right] \\
& +\frac{b_{1}}{b_{0}}[u(k-2)-u(k-1)],
\end{aligned}
$$

where $a_{1}, a_{2}$, and $b_{1}$ are the system parameters to be identified. According to (14) and (15), if $b_{0}$ and $g_{0}$ are selected adequately, the expected closed-loop pole points will be acquired. Selftuning controller is of better characteristics tracing ability to adapt different control objectives, especially for temperature control.

Based on the above hypothesis, the transfer function of temperature control method for DTY machine is described as

$$
G(s)=\frac{G\left(T_{1}\right)}{G(Q)}=\frac{K_{c}\left(T_{4} s+1\right)}{T_{5}^{2} s^{2}+2 \varsigma T_{5} s+1},
$$




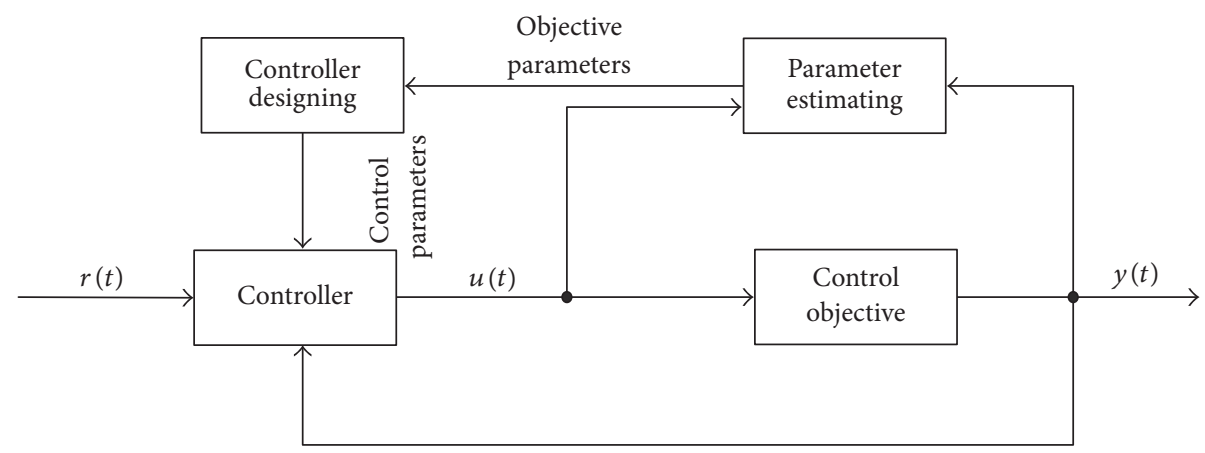

FIGURE 5: Schematic diagram of self-tuning controller.

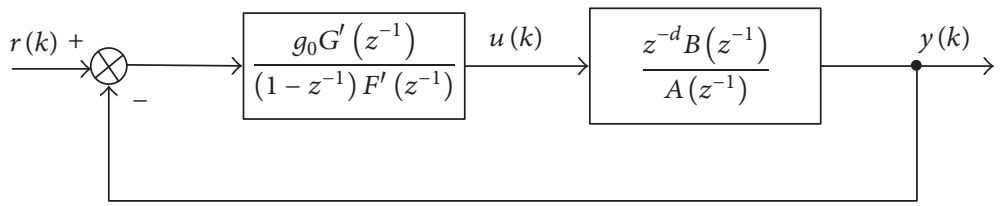

FIGURE 6: Schematic diagram of closed-loop control system.

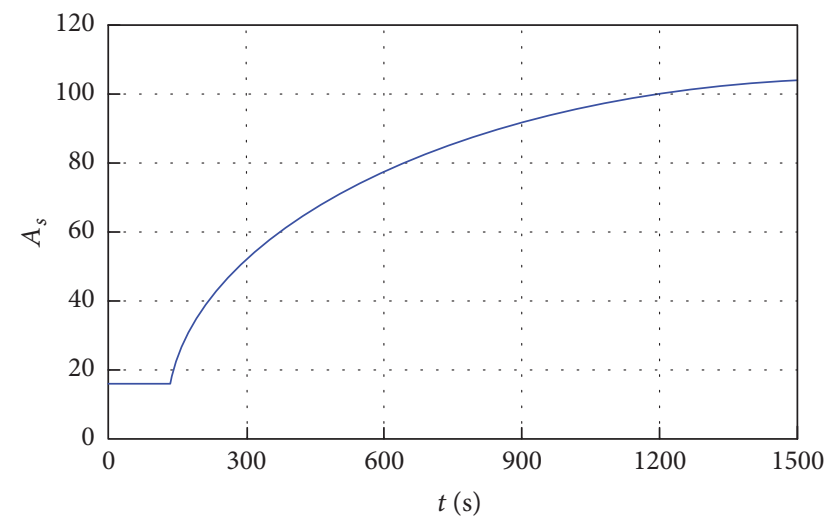

FIGURE 7: Step response of control objective.

where $K_{c}=\left(k_{12}+k_{23}\right) / k_{12} k_{23}, T_{5}^{2}=c_{1} c_{2} / k_{12} k_{23}, T_{4}=$ $c_{2} / k_{12} k_{23}$, and $\varsigma=(1 / 2)\left(\left(c_{1} k_{12}+c_{1} k_{23}+c_{2} k_{12}\right) / \sqrt{c_{1} c_{2} k_{12} k_{23}}\right)$.

The step response of the temperature control objective is shown in Figure 7, and there is no oscillation phenomenon. Therefore, it can be inferred that $\varsigma>1$, and (16) can be revised as

$$
G(s)=\frac{K^{\prime}\left(s+s_{1}\right)}{\left(s+s_{2}\right)\left(s+s_{3}\right)},
$$

where $s_{1}, s_{2}$, and $s_{3}$ are real roots. Concerning the factual temperature control, (17) needs to be processed by $Z$-transform with zero-order hold $(\mathrm{ZOH})$, and the discrete system model is described as

$$
\begin{aligned}
G_{d}(z) & =\left(1-z^{-1}\right) Z\left[\frac{G(s)}{s}\right] \\
& =\left(1-z^{-1}\right) Z\left[\frac{K^{\prime}\left(s+s_{1}\right)}{s\left(s+s_{2}\right)\left(s+s_{3}\right)}\right] \\
& =\frac{b_{0} z+b_{1}}{z^{2}+a_{1} z+a_{2}},
\end{aligned}
$$

where

$$
\begin{aligned}
a_{1} & =-\left(e^{-s_{2} T_{0}}+e^{-s_{3} T_{0}}\right), \\
a_{2} & =e^{-\left(s_{2}+s_{3}\right) T_{0}}, \\
b_{0} & =\frac{K^{\prime}}{s_{2} s_{3}\left(s_{2}-s_{3}\right)}\left[s_{3}\left(s_{1}-s_{2}\right) e^{-s_{2} T_{0}}\right. \\
& \left.+s_{2}\left(s_{3}-s_{1}\right) e^{-s_{3} T_{0}}+s_{1}\left(s_{2}-s_{3}\right)\right], \\
b_{1} & =\frac{K^{\prime}}{s_{2} s_{3}\left(s_{2}-s_{3}\right)}\left[s_{1}\left(s_{2}-s_{3}\right) e^{-\left(s_{2}+s_{3}\right) T_{0}}\right. \\
& \left.+\left(s_{1}-s_{2}\right) s_{3} e^{-s_{3} T_{0}}-s_{2}\left(s_{1}-s_{3}\right) e^{-s_{2} T_{0}}\right] .
\end{aligned}
$$

Then, let $y(k)=T_{d}(k)$ and $u(k)=Q(k)$; the system difference model is expressed as

$$
\begin{aligned}
& y(k)+a_{1} y(k-1)+a_{2} y(k-2) \\
& =b_{0} u(k-d)+b_{1} u(k-d-1)+e(t),
\end{aligned}
$$

where $d$ represents the lagging sampling period number. Subsequently, referring to (20), the system control diagram is shown in Figure 8.

\section{Parameter Identification and Pole-Point Assignment Method}

4.1. System Parameter Identification. Parameter identification is the key task for the effectiveness of the proposed self-tuning PID temperature control method. Regarding the temperature control model in Section 3, to reduce the computation load, the RLS method is adopted to restrict the error of 


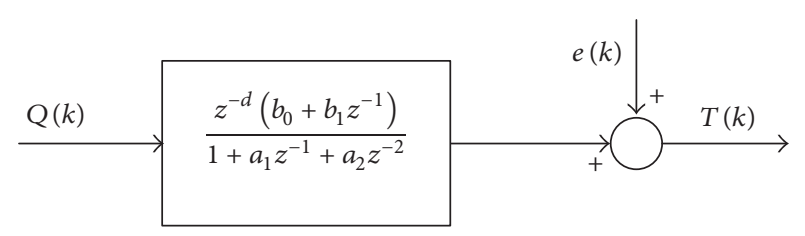

FIGURE 8: Schematic diagram of temperature control system of DTY machine.

parameter estimation values and factual observation values and approximate it to the factual system output [32-35].

According to the control objective characteristics of DTY machine, we can obtain the closed-loop control block diagram of system parameter identification, as shown in Figure 9.

The $Z$-transfer function expression of the above model is

$$
\begin{aligned}
& G(z) \\
& \quad=\frac{1}{1-z^{-1}}\left[K_{P}\left(1-z^{-1}\right)+K_{I}+K_{D}\left(1-z^{-1}\right)^{2}\right] .
\end{aligned}
$$

Equation (21) can be represented as

$$
G(z)=\frac{g_{0}+g_{1} z^{-1}+g_{2} z^{-2}}{1-z^{-1}} .
$$

From the above formulae, we can find that the system parameter identification model is a second-order controller, and the order number equals the order number of temperature control objective of DTY machine. Therefore, it can satisfy the parameter conditions of closed-loop systems.

4.2. Pole-Point Assignment. System point assignment is an essential factor to the factual working performance of the proposed self-tuning PID temperature controller. Pole assignment of self-tuning controller is based on normal control strategy, and the steps are described as follows: (1) acquiring the expected pole-point position of a closed-loop system; (2) estimating and identifying the system parameters online; (3) obtaining the parameters of controller; (4) calculating the efficiency of controller. As mentioned in Section 4.1, the temperature control objective of DTY machine is a second-order system, so the closed-loop transfer function can be expressed by

$$
\frac{y(k)}{r(k)}=\frac{\left(g_{0}\left(1+g_{1}^{\prime} z^{-1}+g_{2}^{\prime} z^{-2}\right) /\left(1-z^{-1}\right)\left(1+f^{\prime} z^{-1}\right)\right) \cdot\left(\left(z^{-d} \cdot b_{0}\left(1+\left(b_{1} / b_{0}\right) z^{-1}\right)\right) /\left(1+a_{1} z^{-1}+a_{2} z^{-2}\right)\right)}{1+\left(g_{0}\left(1+g_{1}^{\prime} z^{-1}+g_{2}^{\prime} z^{-2}\right) /\left(1-z^{-1}\right)\left(1+f^{\prime} z^{-1}\right)\right) \cdot\left(\left(z^{-d} \cdot b_{0}\left(1+\left(b_{1} / b_{0}\right) z^{-1}\right)\right) /\left(1+a_{1} z^{-1}+a_{2} z^{-2}\right)\right)} .
$$

Form (23), the zero points of control targets transfer function are located in the left-half plane of root plane, so it is a classical minimum phase system. For the above system, we can let

$$
\begin{aligned}
1+g_{1}^{\prime} z^{-1}+g_{2}^{\prime} z^{-2} & =1+a_{1} z^{-1}+a_{2} z^{-2}, \\
1+\frac{b_{1}}{b_{0}} z^{-1} & =1+f^{\prime} z^{-1}
\end{aligned}
$$

where $g_{2}^{\prime}=a_{2}, g_{1}^{\prime}=a_{1}$, and $f^{\prime}=b_{1} / b_{0}$.

Consequently, we can acquire the relationship of objective parameters and controller parameters, and the expression is described as

$$
\begin{aligned}
G(z)= & \frac{g_{0}\left(1+g_{1}^{\prime} z^{-1}+g_{2}^{\prime} z^{-2}\right)}{\left(1-z^{-1}\right)\left(1+f^{\prime} z^{-1}\right)} \\
= & \frac{g_{0}\left(1+a_{1} z^{-1}+a_{2} z^{-2}\right)}{\left(1-z^{-1}\right)\left(1+\left(b_{1} / b_{0}\right) z^{-1}\right)}, \\
u(k)= & u(k-1)+g_{0} e(k)+g_{0} \hat{a_{1}} e(k-1) \\
& +g_{0} \hat{a_{2}} e(k-2) \\
& +\frac{\hat{b_{1}}}{\hat{\wedge}}[u(k-2)-u(k-1)], \\
& \hat{b}_{0}
\end{aligned}
$$

where $\hat{a}_{1}, \hat{a_{2}}, \hat{b_{0}}$, and $\hat{b_{1}}$ are the system parameters obtained by online identification, respectively. So the PID control parameters can trace the variation of control objectives, and the system control effectiveness can be improved.

During the RLS-based system parameter identification, the data saturation can influence the identifying accuracy and cause negative effects for the temperature control system $[36,37]$. To address the matter, an ANN-based forgetting factor searching (ANN-FFS) algorithm is proposed, and the steps are described as follows.

(1) A RLS model for parameter identification is set up:

$$
\begin{aligned}
& z(k)+a_{1} z(k-1)+a_{2} z(k-2) \\
& =b_{0} u(k-1)+b_{1} u(k-2)+\varepsilon(k),
\end{aligned}
$$

where $\varepsilon(k)$ is the iteration error that is the difference between the current output and expected output.

(2) In an empirical forgetting factor dataset, the initial values of weights and thresholds are selected, and the neural network is initialized.

(3) The feature data of the target object is input by the input layer neurons, and, after the transition actions of weights, thresholds, and the action function, the network output is obtained.

(4) If $\varepsilon(k)$ is less than the expected error, then the algorithm ends; otherwise, it proceeds to the next step. 


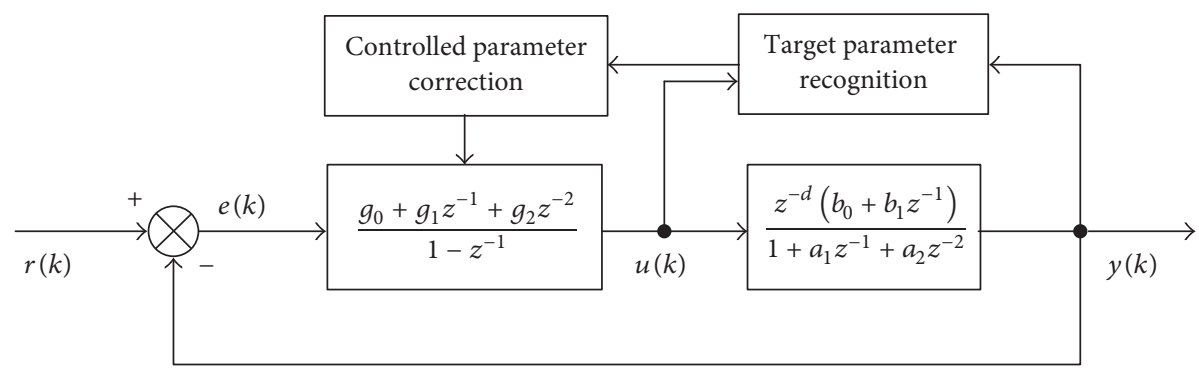

FIGURE 9: System parameter identification closed-loop control block diagram.

TABLE 1: Parameter list for model identification.

\begin{tabular}{|c|c|c|c|c|c|c|c|c|}
\hline \multirow{2}{*}{ Parameter } & \multicolumn{2}{|c|}{$a_{1}$} & \multicolumn{2}{|c|}{$a_{2}$} & \multicolumn{2}{|c|}{$b_{0}$} & \multicolumn{2}{|c|}{$b_{1}$} \\
\hline & $K<15$ & $K>15$ & $K<15$ & $K>15$ & $K<15$ & $K>15$ & $K<15$ & $K>15$ \\
\hline Truth value & 1.50 & 1.25 & 0.90 & 0.55 & 0.15 & 0.09 & 0.008 & 0.002 \\
\hline
\end{tabular}

(5) The connection weights from the output layer to the hidden layer and the output layer neuron thresholds are modified by the following expressions:

$$
\begin{aligned}
& \xi_{j}(n+1)= \xi_{j}(n)+\eta_{n} \sum_{p} \delta_{j} O_{p j} \\
&+\alpha\left[\xi_{j}(n)-\xi_{j}(n-1)\right], \\
& \theta(n+1)= \theta(n)+\eta_{n} \sum_{p} \delta_{j}+\alpha[\theta(n)-\theta(n-1)], \\
& \eta_{n}=\eta_{0}\left[1-\frac{1}{(N+M)}\right],
\end{aligned}
$$

where $\xi_{j}$ is the connection weights from the hidden layer to output layer, $n$ is the number of modifications, $\eta_{n}$ is the iterative interval, $\delta_{j}$ are the neuron errors of hidden layer, $\alpha \in(0,1)$ is the momentum factor, $\theta$ is the neuron threshold of the output layer, $N$ is the number of iterations, and $M$ is a positive integer.

(6) The connection weights from the input layer to the hidden layer and the hidden layer neuron thresholds are modified by the following expressions:

$$
\begin{aligned}
\xi_{i j}(n+1)= & \xi_{i j}(n) \\
& +\eta_{n} \sum_{p} \delta_{i j} O_{p j}+\alpha\left[\xi_{i j}(n)-\xi_{i j}(n-1)\right], \\
\theta_{j}(n+1)= & \theta_{j}(n)+\eta_{n} \sum_{p} \delta_{i j}+\alpha\left[\theta_{j}(n)-\theta_{j}(n-1)\right], \\
\eta_{n}= & \eta_{0}\left[1-\frac{1}{(N+M)}\right],
\end{aligned}
$$

where $\xi_{i j}$ are the connection weights from the input layer to the hidden layer, $\delta_{i j}$ is the neuron error of the output layer, and $\theta_{j}$ is the neuron threshold of the hidden layer.

(7) Does the algorithm arrive at the maximum number of training processes? If so, the iteration ends; otherwise, it returns to step (2).

\section{Numerical Simulation and Results Discussion}

5.1. Forgetting Factor Searching. Related research works suggested that the forgetting factor selection is connected with the system gain factor. For the larger gain factor, the forgetting factor should select smaller values; on the contrary, the larger forgetting factors should be configured. Consequently, the proposed ANN-FFS algorithm can adapt the gain variations of different systems and output better identification results.

To check the effectiveness of the proposed ANN-FFS algorithm, the two groups of comparative experiments for the four parameters $\left(a_{1}, a_{2}, b_{0}\right.$, and $\left.b_{1}\right)$ have been performed, the parameter truth values are listed in Table 1 , and the results are shown in Figures 10-13.

According to the identification results of $a_{1}$ in Figure 10, the following results can be obtained. (1) The two methods can perform parameter identification in less than 650 iteration steps, and the proposed ANN-FFS algorithm is of better convergence performance, especially for the case with smaller gain factor. (2) In Figure 10(a), the convergence step numbers of ANN-FFS and pole assignment are 498 and 612, respectively, so the proposed method can increase the identification efficiency by $18.6 \%$, with smaller error oscillation range. (3) In Figure 10(b), the two methods can converge in less than 400 steps, and the parameter identification is apt to be performed for larger gain factor. The convergence step numbers of the two methods are 365 and 387, respectively, so the convergence advantage of the proposed method tends to be lower.

From the identification curves of $a_{2}$ in Figure 11, we can conduct the following conclusions. (1) Like the identification results of $a_{1}$, the two methods can obtain the expected parameter value in less than 600 iteration steps. (2) The proposed ANN-FFS algorithm has higher parameter identification efficiency, and the advantage becomes apparent by the increment of gain factor. (3) In Figure 11(a), the iteration error curve of pole assignment shows remarkable oscillation, and the proposed method can obtain more stable iteration results. The convergence step numbers of the two methods are 382 and 598, respectively, so the proposed method can increase 


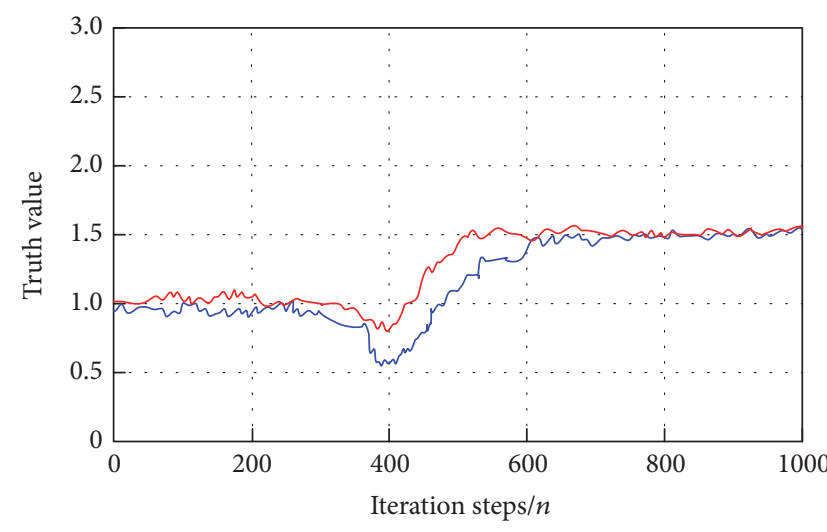

ANN-FFS

Pole assignment

(a)

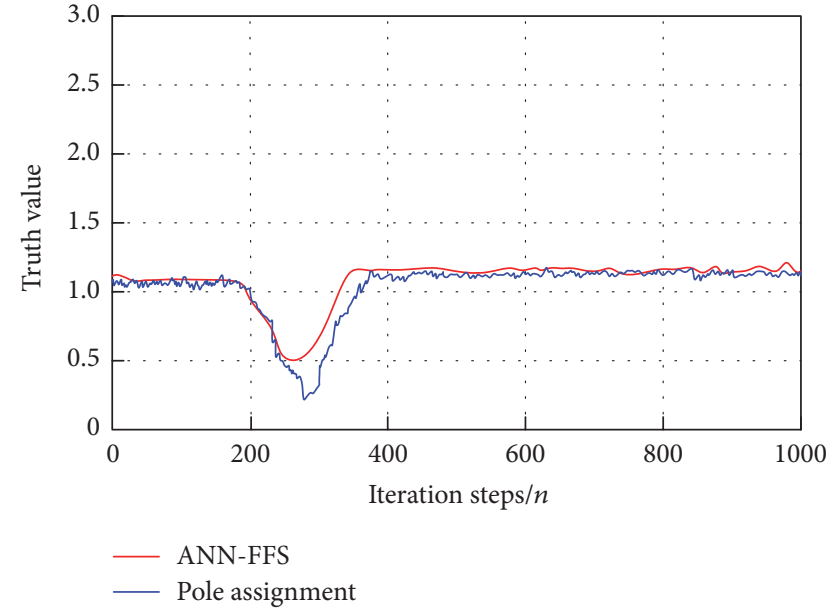

(b)

FIgURE 10: Identification results for parameter $a_{1}$ : (a) $K<15$; (b) $K>15$.

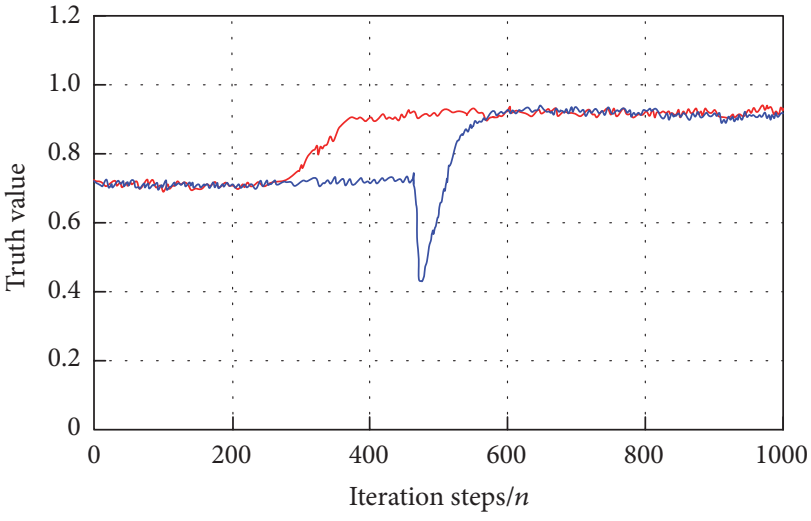

ANN-FFS

Pole assignment

(a)

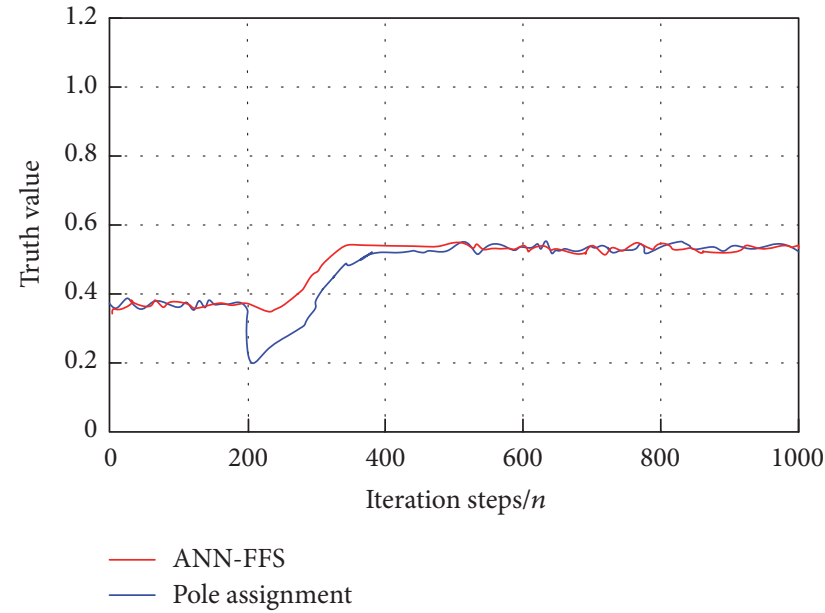

(b)

FIGURE 11: Identification results for parameter $a_{2}$ : (a) $K<15$; (b) $K>15$.

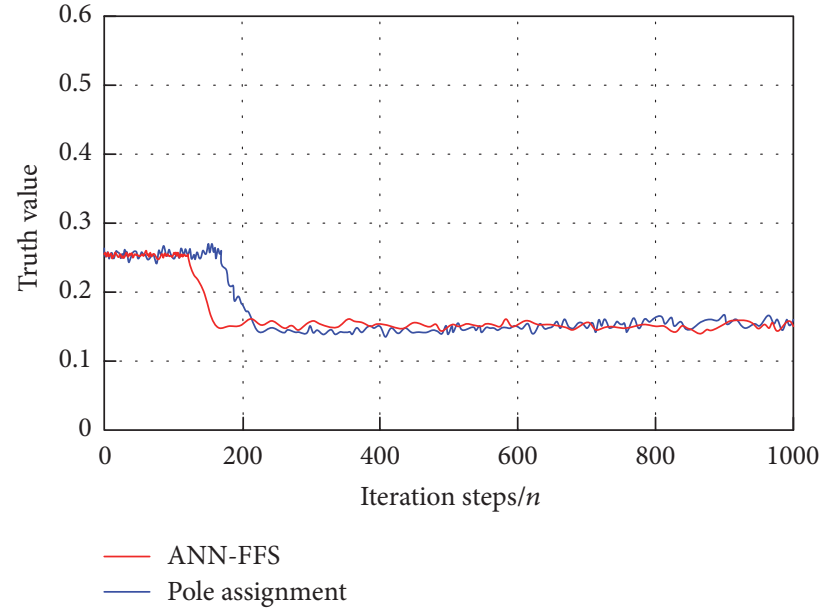

(a)

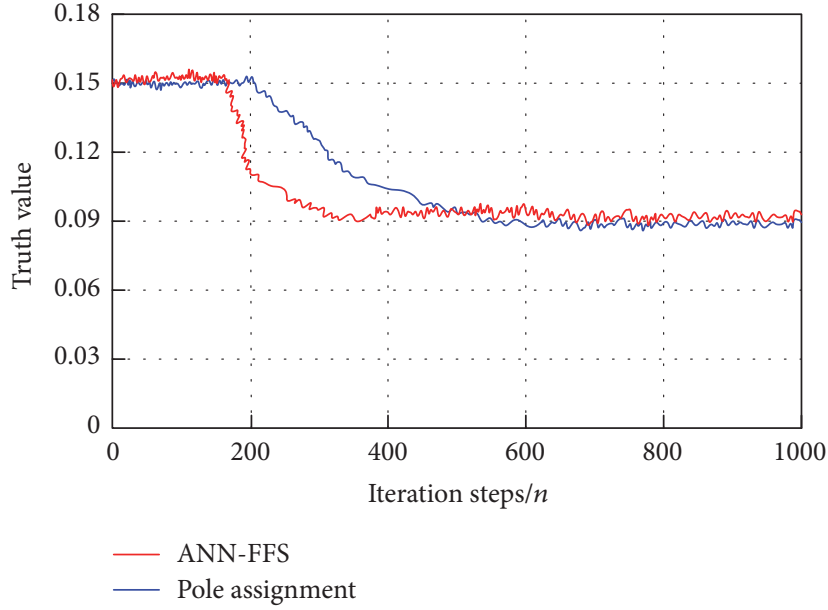

(b)

FIGURE 12: Identification results for parameter $b_{0}$ : (a) $K<15$; (b) $K>15$. 


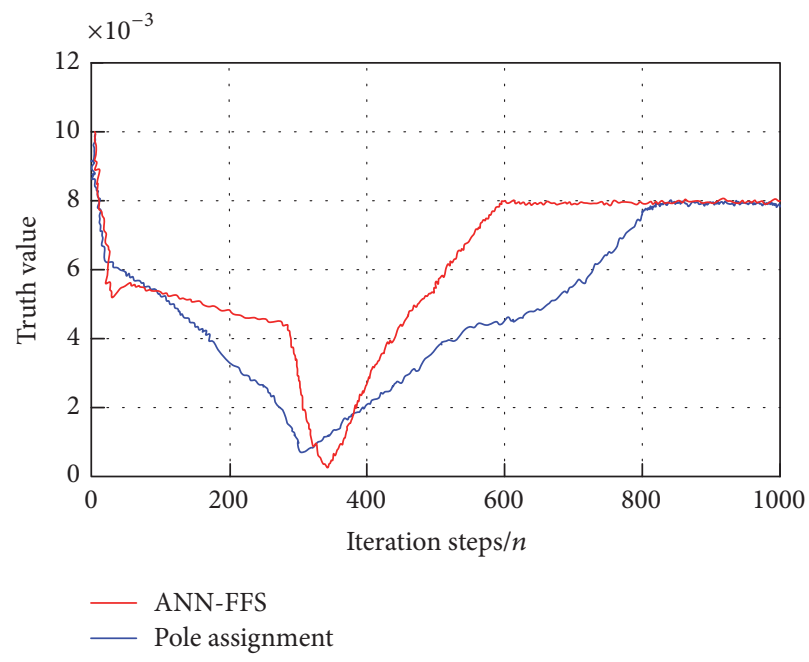

(a)

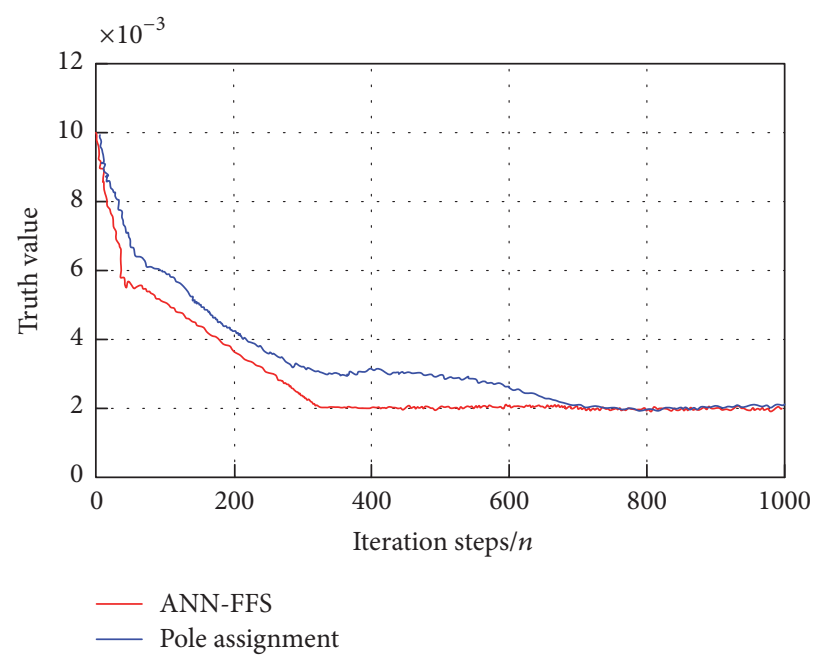

(b)

FIGURE 13: Identification results for parameter $b_{1}$ : (a) $K<15$; (b) $K>15$.

the identification efficiency by $36.1 \%$. (4) In Figure 11(b), the two methods can also converge in less than 400 steps, but the iteration error oscillation still exist on the identification curve of pole assignment. The convergence step numbers of the two methods are 358 and 385, respectively, so the convergence advantage of the proposed method decreases to $7 \%$.

Referring to the identification iteration process about $b_{0}$ (shown in Figure 12), the following results can be obtained. (1) Compared with the identification results of $a_{1}$ and $a_{2}$, identification iteration for $b_{0}$ needs lower computation load.

(2) The two methods can converge in less than 500 iteration steps, without apparent iteration error oscillation phenomena. (3) The proposed ANN-FFS algorithm also can be of better identification efficiency, especially for smaller gain factor. (4) In Figure 12(a), the convergence step numbers of ANNFFS and pole assignment are 175 and 218, respectively, so the proposed method can increase the identification efficiency by 19.7\%. (5) In Figure 12(b), different from the results of $a_{1}$ and $a_{2}$, the two methods can converge in more than 300 steps, which proves that the parameter identification for larger gain factor requires more iteration steps. The convergence step numbers of the two methods are 258 and 542, respectively, so the convergence advantage of the proposed method can reach more than $52 \%$.

The identification results for parameter $b_{1}$ are shown in Figure 13, and the following conclusions can be acquired. (1) In Figure 13(a), the iteration curves of the two methods take on apparent oscillation phenomena. For the pole assignment method, the identification computation requires the max iteration step number: 823. The proposed ANN-FFS algorithm can perform parameter identification in less than 600 iteration steps, and the identification efficiency can be increased by more than $27 \%$. (2) In Figure 13(b), the convergence step numbers of ANN-FFS and pole assignment are 261 and 745, respectively, so the proposed method can obtain the best identification efficiency improvement (65.0\%). The above results prove that the computation load of pole assignment method increases obviously, and the proposed method can perform more stable convergence performance.

5.2. Static Temperature Ascending Process. The static temperature ascending process is the indispensable working procedure of DTY machine heating cabinet and can reflect the primary control performance of the proposed temperature control system. Concerning the issue, the comparative numerical instances with the fuzzy PID method for different working velocities are performed, and the results are shown in Figure 14.

The simulated experimental conditions are set as follows: the fiber material is polyester, the moisture percentage is $30 \%$, the working velocities $\left(v_{s}\right)$ are $600 \mathrm{~m} / \mathrm{min}, 700 \mathrm{~m} / \mathrm{min}$, and $800 \mathrm{~m} / \mathrm{min}$, respectively, the original temperature is $20^{\circ} \mathrm{C}$, the control target temperature is $180^{\circ} \mathrm{C}$, and the control accuracy threshold is $\pm 1^{\circ} \mathrm{C}$.

From the numerical results of static temperature ascending in Figure 14, the following conclusions can be obtained. (1) The proposed ST-PID method and fuzzy PID method can match the control accuracy range $\left( \pm 1^{\circ} \mathrm{C}\right)$ in less than $500 \mathrm{~s}$. (2) By the increment of working velocity, the time-varying characteristics of the control objective tend to be remarkable, so the convergence process for static temperature ascending requires more heating time. (3) In Figure 14(a), the temperature curve of fuzzy PID is of oscillation phenomenon, and the proposed method can obtain more stable control results. The convergence heating time of the two methods is $255 \mathrm{~s}$ and $345 \mathrm{~s}$, respectively, so the proposed method can increase the temperature ascending efficiency by $26.1 \%$. The two methods can all have better control effects, and the control accuracy ranges are $\pm 0.25^{\circ} \mathrm{C}$ and $\pm 0.45^{\circ} \mathrm{C}$, respectively. (4) In Figure 14(b), the proposed method requires lower heating time to perform the temperature ascending convergence. Because of the limited objective tracing ability, the control accuracy of fuzzy PID method decreases apparently, and the 


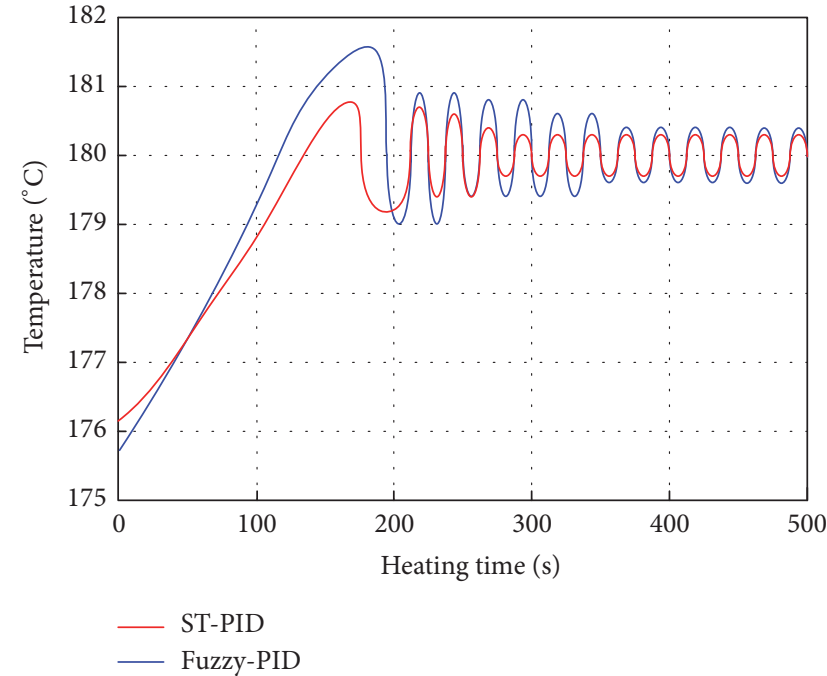

(a)

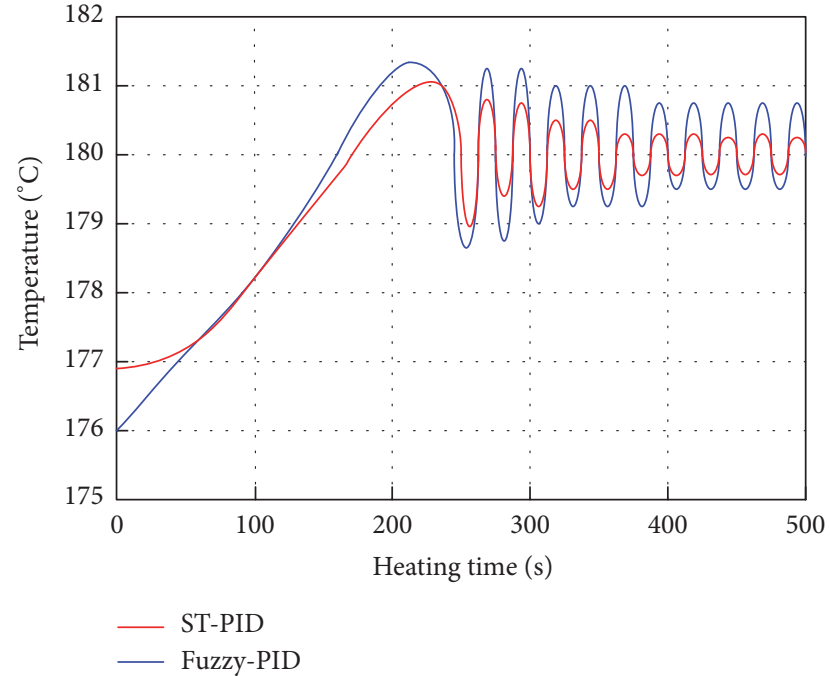

(b)

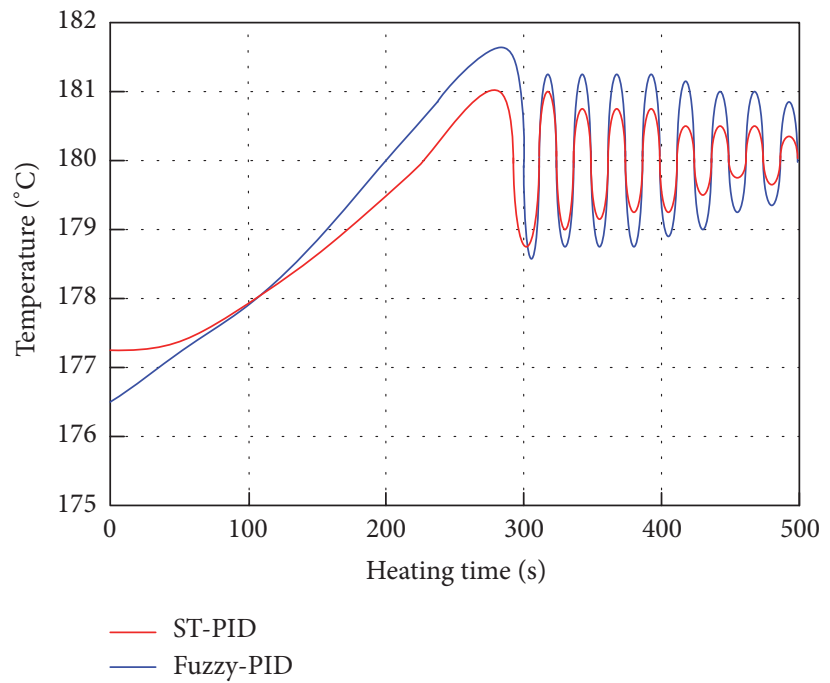

(c)

FIGURE 14: Numerical comparative results of static temperature ascending process: (a) $v_{s}=600 \mathrm{~m} / \mathrm{min},(\mathrm{b}) v_{s}=700 \mathrm{~m} / \mathrm{min}$, and (c) $v_{s}=$ $800 \mathrm{~m} / \mathrm{min}$.

accuracy ranges of the two methods are $\pm 0.27^{\circ} \mathrm{C}$ and $\pm 0.68^{\circ} \mathrm{C}$, respectively. (5) In Figure 14(c), owing to the increment of working velocity, the two methods require more than 400 s to match the temperature ascending convergence. The control accuracy of fuzzy PID method decreases continuously to $\pm 0.85^{\circ} \mathrm{C}$. The proposed method can keep stable control effects, and the control accuracy can increase nearly 3 times compared with the fuzzy PID method.

\section{Industrial Experiments and Results Discussion}

6.1. Embedded ST-PID-Based Temperature Control System. To check the industrial effectiveness of the proposed STPID temperature control method, an embedded ST-PID temperature control system for DTY machine is developed [38-41]. The control system is composed of Cortex-M3 embedded processor, LCD human computer interface (HCI), field programmable gate array (FPGA), RAM memory, A/D converter, multichannel switch, driver circuit, power amplification device, and temperature sensors, as shown in Figure 15.

As indicated in Section 1, a DTY machine not only has the fast time-varying characteristics, but possesses many working channels, that is, the heating cabinets. Therefore, the temperature controller can hold the multichannel control points, with the abilities of multichannel selection, input and output. To address the issue, a FPGA is adopted to extend the I/O ports of embedded processor (shown in Figure 15), and the multichannel temperature control for DTY machine is performed.

Since the working temperature of DTY heating cabinet is apt to be disturbed by the environmental factors of fiber material, fiber moisture percentage, tensile speed, ambient temperature, and heating power, the anti-interference scheme 


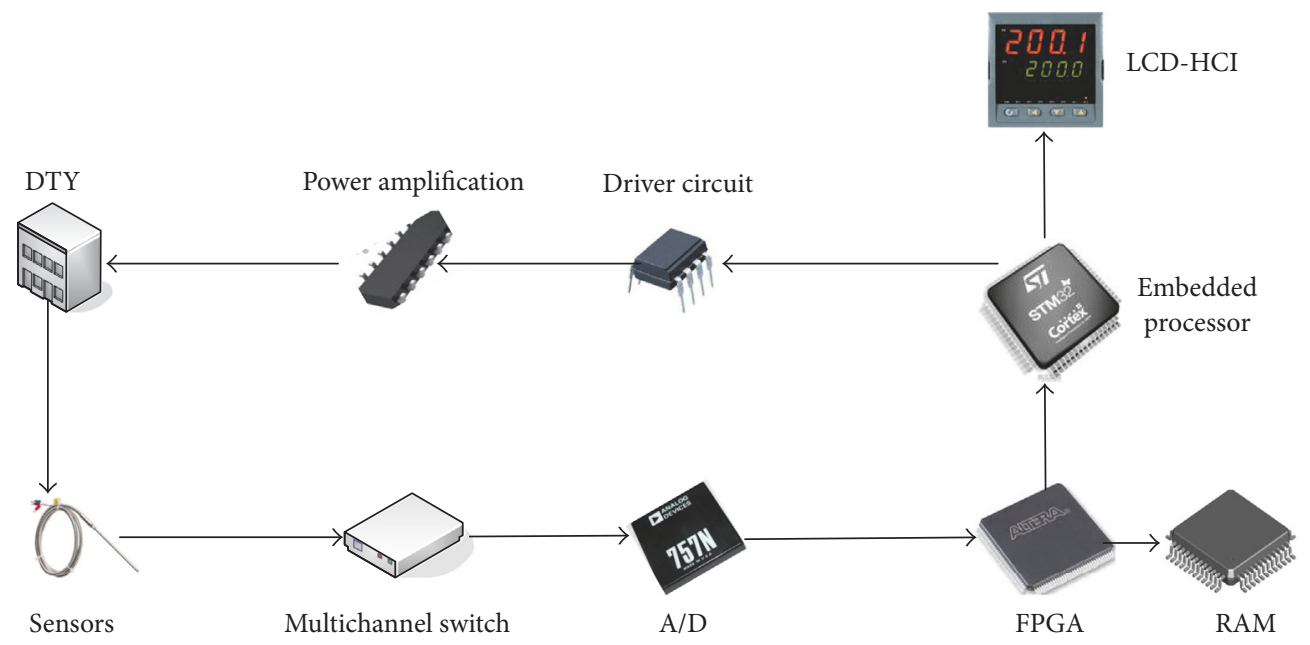

FIGURE 15: Hardware structure of embedded ST-PID-based temperature control system.

is an indispensable component of the temperature control system [42-45]. Considering the above matter, two methods are adopted to resolve it. In the facet of hardware, some anti-interference measures such as optoelectronic isolating should be implemented. For the software, the system selfcheck program is developed according to related working conditions, in which the monitor timer (watch dog) and interrupt program are adopted to improve the system stability. As shown in Figure 16, by the monitor time and interrupt program, the system control procedure can be divided into three independent branches: main program, A/D interrupt program, and timer interrupt program. The above scheme can perform parallel task processing and mutex operation for the data acquisition and temperature control.

\subsection{Comparative Experiments and Results Discussion}

6.2.1. Temperature Ascending Process. As mentioned in Section 5, as a key technical procedure of DTY machine, the static temperature ascending process can characterize the fundamental control effects of the developed temperature control system. Consequently, the comparative experiments with the fuzzy PID method for the static temperature ascending process at different working velocities are performed, and the results are shown in Figure 17. The experimental conditions are described as follows: the fiber moisture percentage is $33 \%$, the average working velocities $\left(v_{e}\right)$ are $620 \mathrm{~m} / \mathrm{min}, 730 \mathrm{~m} / \mathrm{min}$, and $810 \mathrm{~m} / \mathrm{min}$, respectively, the original temperature is $40^{\circ} \mathrm{C}$, the control target temperature is $180^{\circ} \mathrm{C}$, and the control accuracy threshold is $\pm 1^{\circ} \mathrm{C}$. If the control accuracy exceeds $\pm 2^{\circ} \mathrm{C}$, it cannot satisfy the practical technical requirement of fiber heating.

According to the comparative experimental results of temperature ascending in Figure 17, we can obtain the following conclusions. (1) The experimental results are in accord with the numerical simulation results in Figure 14. The proposed ST-PID method and fuzzy PID method can match the expected control range $\left( \pm 1^{\circ} \mathrm{C}\right)$ in less than $600 \mathrm{~s}$. (2) By the increment of working velocity, the heating time for the expected temperature threshold increases apparently. Compared with the numerical results, the factual static temperature ascending process requires more heating time due to the peripheral environmental factors. (3) In Figure 17(a), the temperature variation range of fuzzy PID method exceeds $\pm 1^{\circ} \mathrm{C}$ in the earlier $300 \mathrm{~s}$, and the proposed method can obtain more stable control effects with the control accuracy $\pm 0.27^{\circ} \mathrm{C}$. Different from the numerical results, the control accuracy of fuzzy PID decreases to $\pm 0.75^{\circ} \mathrm{C}$, which proves that it is apt to be influenced by the environmental interferences. (4) In Figure 17(b), the proposed ST-PID method can obtain better static temperature ascending efficiency. The temperature curve of fuzzy PID still shows oscillation phenomenon, and the control accuracy decreases to $\pm 0.75^{\circ} \mathrm{C}$. For the objective tracing ability and anti-interference scheme, the control accuracy of the proposed method shows only a slight decrease, and the accuracy range is $\pm 0.30^{\circ} \mathrm{C}$. (5) In Figure $17(\mathrm{c})$, owing to the increment of working velocity, the two methods require the max heating time to match the temperature ascending threshold. The control accuracy of fuzzy PID method decreases continuously to $\pm 0.98^{\circ} \mathrm{C}$. The proposed method can keep the accuracy range to less than $\pm 0.32^{\circ} \mathrm{C}$, and the control accuracy can increase more than 3 times.

6.2.2. Steady State Control Effects. Steady state control effects are the most important technical indexes of control systems. In order to verify the validation and superiority of the proposed ST-PID control method, the comparative experiments with the fuzzy PID control method have been implemented.

During the course of the experiments, by the increasing of temperature, the fiber moisture percentage will decline continuously. When the moisture percentage decreases to $20 \%$, the evaporation rate tends to be accelerating, and the thermal conductivity of fiber will decline rapidly. The above physical process can cause the remarkable variation of control objective and can be regarded as an objective switching process. Accordingly, to check the objective tracing and antiinterference performances of the proposed ST-PID method, 


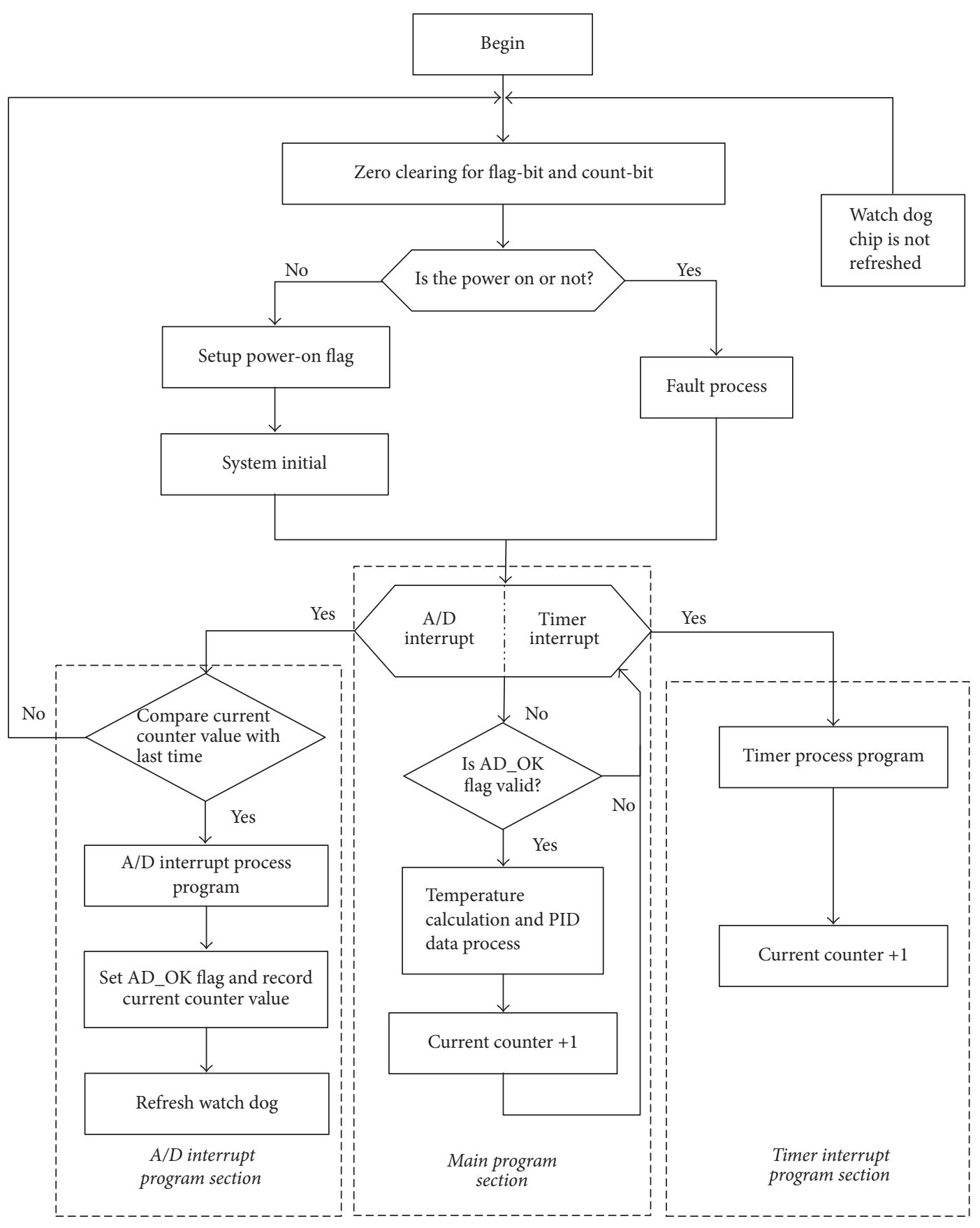

FIGURE 16: System monitoring software process flow.

the selected time segments for steady control experiments contain the objective switching process, and the results are shown in Figure 18.

From the comparative results of steady state control effects in Figure 18, the following conclusions can be inferred. (1) For the moisture stage, the proposed ST-PID method and fuzzy PID method can match the expected control range $\left( \pm 1^{\circ} \mathrm{C}\right)$, that is, keeping the steady state variation trend after the temperature ascending. (2) At the moment of objective switching, the temperature curves of fuzzy PID method show severe fluctuation, and the fluctuation amplitude increases with the increment of working velocity. On the contrary, since the proposed ST-PID method is of the better abilities of characteristics tracing and anti-interference, it can adapt the remarkable variation of objective and restrain the temperature fluctuation in the range of $\pm 0.85^{\circ} \mathrm{C}$. (3) For the dried stage, the control accuracy of fuzzy PID method decreases apparently, even exceeding the expected control range. The proposed method can have stable control effects, and the temperature variation can be limited in the range of $\pm 0.55^{\circ} \mathrm{C}$. 


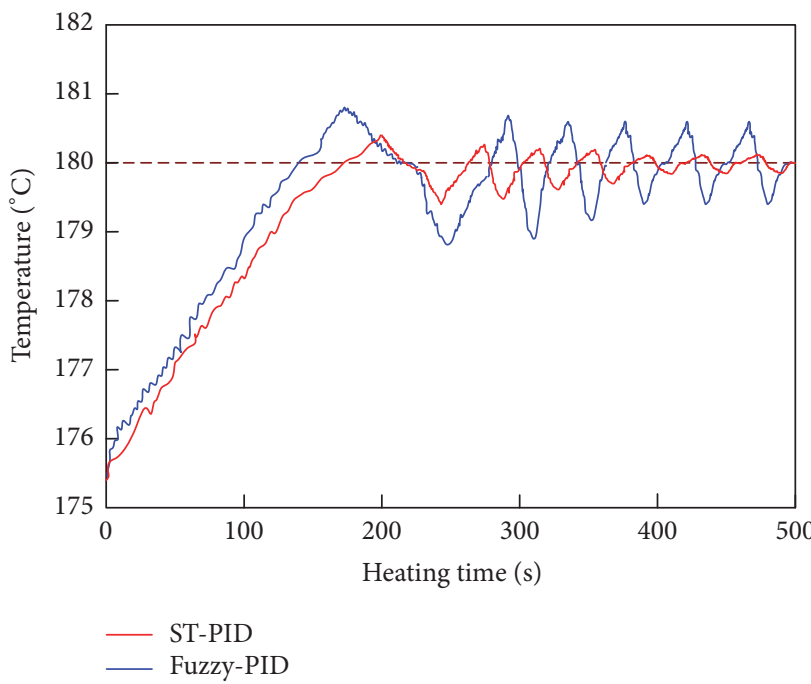

(a)

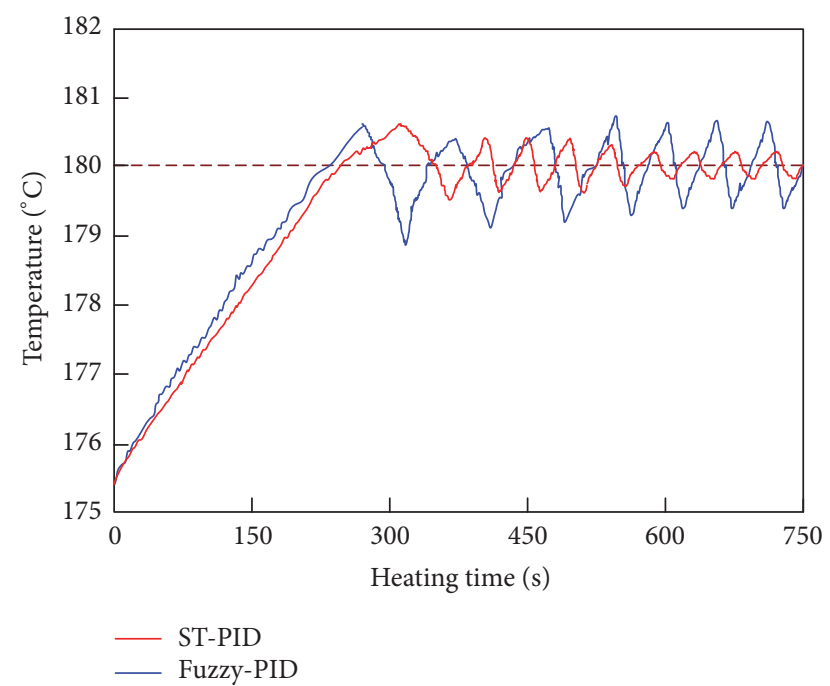

(b)

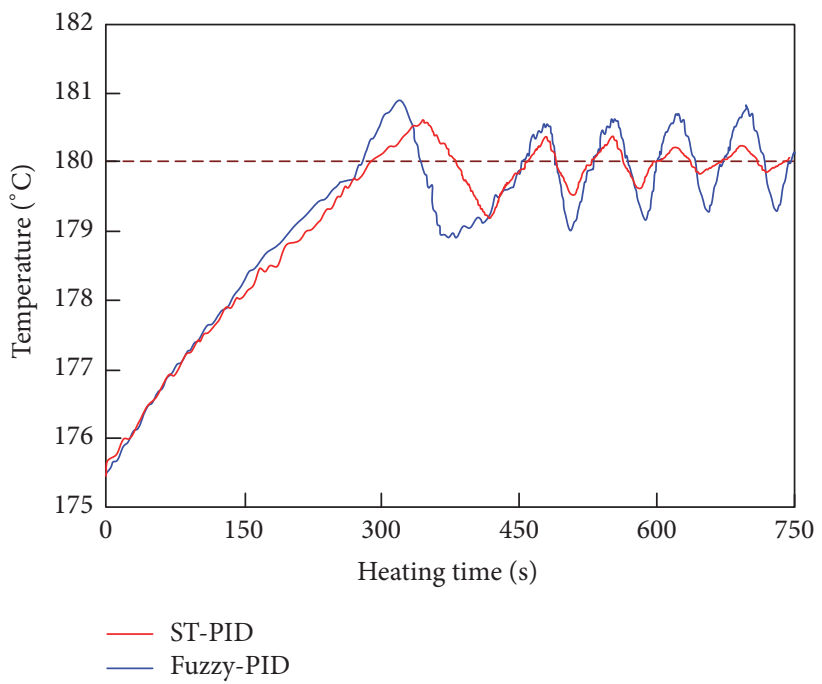

(c)

FIGURE 17: Comparative experimental results of static temperature ascending process: (a) $v_{e}=620 \mathrm{~m} / \mathrm{min},(\mathrm{b}) v_{e}=730 \mathrm{~m} / \mathrm{min}$, and (c) $v_{e}=810 \mathrm{~m} / \mathrm{min}$.

(4) In Figure 18(a), the temperature fluctuation of fuzzy PID at $900 \mathrm{~s}$ is larger than $\pm 1.50^{\circ} \mathrm{C}$, and the control accuracy range narrowly satisfies the expected threshold. The temperature curve of the proposed method shows apparent fluctuation, and the steady control accuracy is less than $\pm 0.40^{\circ} \mathrm{C}$. (5) In Figure 18(b), the temperature switching fluctuation of fuzzy PID can reach $\pm 2.20^{\circ} \mathrm{C}$, which will cause negative influence to normal textile production. The steady control accuracy of fuzzy PID has exceeded the expected threshold, while the proposed method can make the steady accuracy be in the range of $\pm 0.45^{\circ} \mathrm{C}$. (6) In Figure 18 (c), by the increment of working velocity, the temperature switching fluctuation of fuzzy PID can reach $\pm 2.80^{\circ} \mathrm{C}$, and the steady control accuracy decreases to $\pm 1.50^{\circ} \mathrm{C}$. The proposed method can keep stable control effects, and the control accuracy can increase nearly 3 times.

\section{Conclusion}

DTY machine has multiple production channels and fast time-varying characteristics, which bring forward technical challenges for the temperature control systems. This paper addresses the issue by proposing a ST-PID-based temperature control method. With respect to the above research target, the corresponding research works have been performed, and the main conclusions are as follows.

(1) According to the thermodynamic characteristics of DTY machine heating cabinet, a discrete mathematics model is set up, and the heat transfer results of the control objective are acquired.

(2) A ST-PID temperature controller for DTY machine is designed, and the minimum phase control system is constructed by the pole assignment method. To improve the 


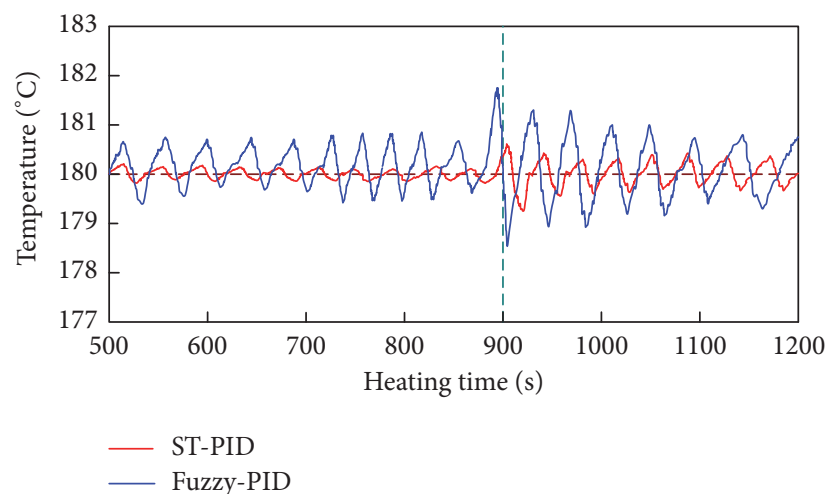

(a)

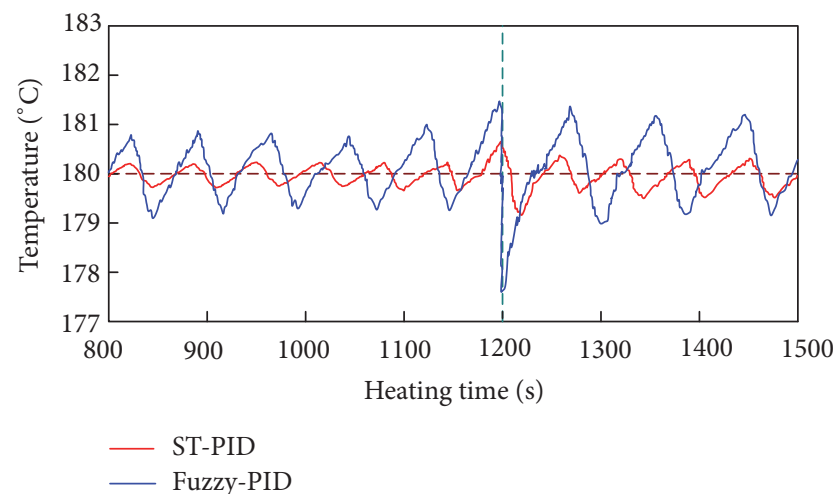

(b)

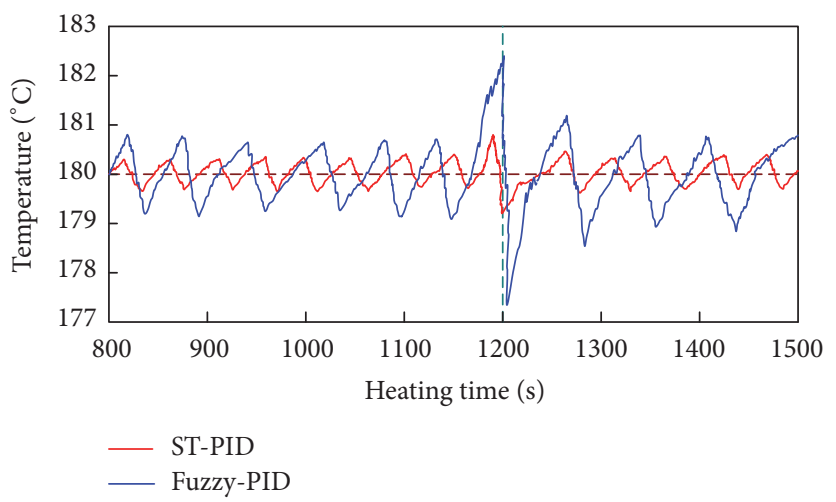

(c)

FIGURE 18: Comparative experimental results of steady state control effects: (a) $v_{e}=620 \mathrm{~m} / \mathrm{min}$, (b) $v_{e}=730 \mathrm{~m} / \mathrm{min}$, and (c) $v_{e}=810 \mathrm{~m} / \mathrm{min}$.

parameter identification efficiency, an ANN-FFS algorithm is proposed, which can resolve the data saturation of identification computation.

(3) Two numerical cases are provided, and the simulated results show that the proposed ANN-FFS algorithm can optimize the parameter identification process, and the average identifying efficiency for different gain factors $(K<$ $15 ; K>15)$ can increase by more than $25 \%$ and $50 \%$, respectively, compared with the pole assignment method; the proposed ST-PID method can obtain stable control effects for the static temperature ascending process, and the control accuracy can increase nearly 3 times, compared with the fuzzy PID controller.

(4) An embedded ST-PID temperature control system for DTY machine is developed, and the comparative industrial experiments have been performed. The experimental results prove that the proposed ST-PID method has better abilities of objective characteristics tracing and anti-interference and can restrain the temperature fluctuation caused by objective switching; it can obtain stable steady state control effects, and the factual control accuracy reaches 3 times that of fuzzy PID method.

To sum up, the key scientific contribution of the paper is providing a ST-PID modeling method and a dynamical parameter identifying method for the fast time-varying objectives. This research not only can offer theoretical references to the control system modeling-solving and energy conservation of fast time-varying process, but can supply direct technical evidences for control system development and energy performance optimization involved in the industrial areas of metallurgy automatic control, mechatronic system monitoring, and pressure vessel maintenance. The subsequent research works will be performed on the computational fluid dynamics (CFD) based heat transfer modeling and real-time parallel control methods.

\section{Nomenclature}

$a_{i}:$ System output parameters

$A_{1}$ : Heat transfer area from air cell to insulating layer

$A_{2}$ : Heat transfer area from insulating layer to outside air

$A_{r}$ : Radiating coefficient

$b_{i}$ : System excitation parameters

$c_{1}$ : Specific heat constant from input to air cell

$c_{2}$ : Specific heat constant insulating layer to outside air

$C$ : System specific heat

$C_{1}$ : Air cell specific heat

$C_{2}$ : Insulation layer specific heat

$C_{3}$ : Outside air specific heat

$C_{d}$ : Time constant 
$d$ : Lagging sampling period number

$D(z)$ : $Z$-transformation of incremental digital PID

$e$ : Natural constant

$e(t)$ : System error

$e(k)$ : Incremental error

$f: \quad$ Filtering element

$g_{0}: \quad$ Zero-order control parameter

$g_{1}$ : First-order control parameter

$g_{2}$ : Second-order control parameter

$G(s)$ : System transfer function

$k$ : Incremental step

$k_{12}$ : Heat transfer constant from air cell to insulating layer

$k_{23}$ : Heat transfer constant from insulating layer to outside air

$K$ : $\quad$ System gain factor

$K^{\prime}$ : $\quad$ ST-PID gain factor

$K_{12}$ : Heat transfer coefficient from air cell to insulating layer

$K_{23}$ : Heat transfer coefficient from insulating layer to outside air

$K_{p}$ : Proportional constant

$m_{1}$ : Air cell mass

$m_{2}$ : Insulating layer mass

$M$ : Positive integer

$N$ : $\quad$ Iteration number

Q: Input heat power

$Q_{12}$ : Heat from air cell to insulating layer

$Q_{23}$ : Heat from insulating layer to outside air

$r(t)$ : Ideal output

$s: \quad$ Complex domain variable

$s_{i}: \quad$ System real roots

$t$ : Time variable

$T_{1}$ : $\quad$ Air cell temperature

$T_{2}$ : Insulation layer temperature

$T_{3}$ : Outside air temperature

$T_{D}$ : Derivative time constant

$T_{I}$ : Integral time constant

$u(t)$ : PID expression

$u(k)$ : Incremental digital PID expression

$v_{e}: \quad$ Experimental working velocity

$v_{s}$ : Simulated working velocity

$y(t)$ : Factual output

$z: \quad Z$-transformation variable.

\section{Greek Symbols}
$\alpha: \quad$ Momentum factor
$\delta_{j}$ : Neuron errors of hidden layer
$\delta_{i j}$ : Neuron error of the output layer
$\varepsilon(k)$ : Iteration error
$\varsigma$ : Damping coefficient of ST-PID
$\eta_{0}$ : Original iterative value
$\eta_{n}: \quad$ Iterative interval
$\theta: \quad$ Neuron threshold of the output layer
$\theta_{j}$ : Neuron threshold of the hidden layer
$\xi_{j}$ : Weights from the hidden layer to output layer
$\xi_{i j}$ : Weights from the input layer to the hidden layer
$\tau$ : $\quad$ System lag time.

\section{Disclosure}

The funders had no role in study design, data collection and analysis, decision to publish, or preparation of the manuscript.

\section{Conflicts of Interest}

The authors declare that there are no conflicts of interest regarding the publication of this paper.

\section{Acknowledgments}

The authors wish to acknowledge the financial supports of the Zhejiang Provincial Health Department Program under Grant no. 2015KYA067 and the Zhejiang Provincial Education Science Plan under Grant nos. 2013SCG386 and 2017SCG028.

\section{References}

[1] H. A. Kim and S. J. Kim, "Moisture and thermal permeability of the hollow textured PET imbedded woven fabrics for high emotional garments," Fibers and Polymers, vol. 17, no. 3, pp. 427438, 2016.

[2] M. H. Shim, J. Kim, and C. H. Park, "Development of superhydrophobic fabrics by surface fluorination and formation of CNT-induced roughness," Medziagotyra, vol. 21, no. 1, pp. 6873, 2015.

[3] X. Yan, L. Xu, and Y. Wang, "The Loading Control Strategy of the Mobile Dynamometer Vehicle Based on Neural Network PID," Mathematical Problems in Engineering, vol. 2017, Article ID 5658983, 7 pages, 2017.

[4] W. Belhaj and O. Boubaker, "MIMO PI controllers for LTI systems with multiple time delays based on ILMIs and sensitivity functions," Mathematical Problems in Engineering, vol. 2017, Article ID 1241545, 25 pages, 2017.

[5] D. Tan, S. Ji, P. Li, and X. Pan, "Development of vibration style ladle slag detection methods and the key technologies," Science China Technological Sciences, vol. 53, no. 9, pp. 2378-2387, 2010.

[6] D. P. Tan and L. B. Zhang, "A WP-based nonlinear vibration sensing method for invisible liquid steel slag detection," Sensors and Actuators B: Chemical, vol. 202, pp. 1257-1269, 2014.

[7] L. Zhang, J. Wang, D. Tan, and Z. Yuan, "Gas compensationbased abrasive flow processing method for complex titanium alloy surfaces," The International Journal of Advanced Manufacturing Technology, vol. 92, no. 9-12, pp. 3385-3397, 2017.

[8] S. M. Attaran, R. Yusof, and H. Selamat, "A novel optimization algorithm based on epsilon constraint-RBF neural network for tuning PID controller in decoupled HVAC system," Applied Thermal Engineering, vol. 99, pp. 613-624, 2016.

[9] M. Trafczynski, M. Markowski, S. Alabrudzinski, and K. Urbaniec, "The influence of fouling on the dynamic behavior of PIDcontrolled heat exchangers," Applied Thermal Engineering, vol. 109, pp. 727-738, 2016.

[10] H. Moradi, H. Setayesh, and A. Alasty, "PID-Fuzzy control of air handling units in the presence of uncertainty," International Journal of Thermal Sciences, vol. 109, pp. 123-135, 2016.

[11] S. Li, X. Li, and Y. Yang, "Intelligent model building and GPCPID based temperature curve control strategy for metallurgical 
industry," Mathematical Problems in Engineering, vol. 2016, Article ID 7454805, 2016.

[12] S. Kanagalakshmi, D. Manamalli, and M. Mohamedrafiq, "Implementation of multimodel-based PID and intelligent controller for simulated and real-time temperature control of injection molding machine," Chemical Engineering Communications, vol. 203, no. 4, pp. 452-462, 2015.

[13] Z. Zhang, C. Ma, and R. Zhu, "Self-tuning fully-connected PID neural network system for distributed temperature sensing and control of instrument with multi-modules," Sensors, vol. 16, no. 10, article 1709, 2016.

[14] D. Pamela and M. S. Godwin Premi, "Wireless Control and Automation of Hot Air Temperature in Oven for Sterilization using Fuzzy PID Controller and Adaptive Smith Predictor," Wireless Personal Communications, vol. 94, no. 4, pp. 20552064, 2016.

[15] J. Zhang, "Design of a new PID controller using predictive functional control optimization for chamber pressure in a coke furnace," ISA Transactions ${ }^{\circledR}$, vol. 67, pp. 208-214, 2017.

[16] J. Chen, F. Xu, D. Tan, Z. Shen, L. Zhang, and Q. Ai, "A control method for agricultural greenhouses heating based on computational fluid dynamics and energy prediction model," Applied Energy, vol. 141, no. 1, pp. 106-118, 2015.

[17] D. Tan, Y. Ni, and L. Zhang, "Two-phase sink vortex suction mechanism and penetration dynamic characteristics in ladle teeming process," Journal of Iron and Steel Research, International, vol. 24, no. 7, pp. 669-677, 2017.

[18] S. Chiriţă, M. Ciarletta, and V. Tibullo, "On the thermomechanical consistency of the time differential dual-phase-lag models of heat conduction," International Journal of Heat and Mass Transfer, vol. 114, pp. 277-285, 2017.

[19] D.-P. Tan, S.-T. Chen, G.-J. Bao, and L.-B. Zhang, "An embedded lightweight GUI component library and the ergonomics optimization method for industry process monitoring," Frontiers of Information Technology \& Electronic Engineering, vol. 1, no. 1, 1998.

[20] X. Zeng, S.-M. Ji, M.-S. Jin, D.-P. Tan, J.-H. Li, and W.-T. Zeng, "Investigation on machining characteristic of pneumatic wheel based on softness consolidation abrasives," International Journal of Precision Engineering and Manufacturing, vol. 15, no. 10, pp. 2031-2039, 2014.

[21] X. Zeng, S.-M. Ji, D.-P. Tan, M.-S. Jin, D.-H. Wen, and L. Zhang, "Softness consolidation abrasives material removal characteristic oriented to laser hardening surface," The International Journal of Advanced Manufacturing Technology, vol. 69, no. 912, pp. 2323-2332, 2013.

[22] D.-P. Tan, T. Yang, J. Zhao, and S.-M. Ji, "Free sink vortex Ekman suction-extraction evolution mechanism," Acta Physica Sinica, vol. 65, no. 5, Article ID 054701, 2016.

[23] W. Mingge, L. Congda, T. Dapeng, H. Tao, C. Guohai, and W. Donghui, "Effects of metal buffer layer for amorphous carbon film of 304 stainless steel bipolar plate," Thin Solid Films, vol. 616, pp. 507-514, 2016.

[24] J. Ge, S. Ji, and D. Tan, "A gas-liquid-solid three-phase abrasive flow processing method based on bubble collapsing," The International Journal of Advanced Manufacturing Technology, pp. 1-17, 2017.

[25] H. Zhan, F. Xu, and Z. Ni, "Fluid dynamic modeling and fuzzy proportional-integral-derivative-based ink-supply method for piezoelectric ink-jet printing," Advances in Mechanical Engineering, vol. 9, no. 7, pp. 1-7, 2017.
[26] C. Li, S.-M. Ji, and D.-P. Tan, "Multiple-loop digital control method for a 400-hz inverter system based on phase feedback," IEEE Transactions on Power Electronics, vol. 28, no. 1, pp. 408417, 2013.

[27] Y. Li, D. Tan, D. Wen, S. Ji, and D. Cai, "Parameters optimization of a novel 5-DOF gasbag polishing machine tool," Chinese Journal of Mechanical Engineering, vol. 26, no. 4, pp. 680-688, 2013.

[28] D.-P. Tan, S.-M. Ji, and M.-S. Jin, "Intelligent computer-aided instruction modeling and method to optimize study strategies for parallel robot instruction," IEEE Transactions on Education, vol. 56, no. 3, pp. 268-273, 2013.

[29] J. Li, S.-M. Ji, and D.-P. Tan, "Improved soft abrasive flow finishing method based on turbulent kinetic energy enhancing," Chinese Journal of Mechanical Engineering, vol. 30, no. 2, pp. 301-309, 2017.

[30] D.-P. Tan, S.-M. Ji, and Y.-Z. Fu, "An improved soft abrasive flow finishing method based on fluid collision theory," The International Journal of Advanced Manufacturing Technology, vol. 85, no. 5-8, pp. 1261-1274, 2016.

[31] S.-M. Ji, J.-Q. Ge, and D.-P. Tan, "Wall contact effects of particlewall collision process in two-phase particle fluid," Journal of Zhejiang University-SCIENCE A (Applied Physics \& Engineering), 2017.

[32] D.-P. TAN, P.-Y. LI, and X.-H. PAN, "Application of Improved HMM Algorithm in Slag Detection System," Journal of Iron and Steel Research, International, vol. 16, no. 1, pp. 1-6, 2009.

[33] C. Li, S.-M. Ji, and D.-P. Tan, "Study on machinability and the wall region of solid-liquid two phase softness abrasive flow," International Journal of Advanced Manufacturing Technology, vol. 61, no. 9-12, pp. 975-987, 2012.

[34] S.-M. Ji, X.-X. Weng, and D.-P. Tan, "Analytical method of softness abrasive two-phase flow field based on 2D model of LSM," ACTA Physica Sinica, vol. 61, no. 1, Article ID 010205, 2012.

[35] R. Sivashanmugam and S. Arumugam, "Robust Adaptive algorithm by an adaptive zero attractor controller of ZA-LMS algorithm," Mathematical Problems in Engineering, vol. 2016, Article ID 3945895, 7 pages, 2016.

[36] S.-T. Chen and D.-P. Tan, "A SA-ANN-based modeling method for human cognition mechanism and the PSACO cognition algorithm," Complexity, In Press.

[37] N. Zheng, L. Su, D. Zhang, L. Gao, M. Yao, and Z. Wu, "A computational model for ratbot locomotion based on cyborg intelligence," Neurocomputing, vol. 170, pp. 92-97, 2015.

[38] D. Tan, P. Li, and X. Pan, "Intelligent industry monitoring network architecture UPnP based," Journal of Electronics, vol. 17, no. 4, pp. 607-610, 2008.

[39] D. Tan, L. Zhang, and Q. Ai, "An embedded self-adapting network service framework for networked manufacturing system," Journal of Intelligent Manufacturing, pp. 1-18, 2016.

[40] X. Zeng, S.-M. Ji, M.-S. Jin, D.-P. Tan, and J.-Q. Ge, "Research on dynamic characteristic of softness consolidation abrasives in machining process," The International Journal of Advanced Manufacturing Technology, vol. 82, no. 5-8, pp. 1115-1125, 2016.

[41] I. Herrera-Leandro, P. Moreno-Villalobos, S. Ortega-Cisneros, J. Rivera, and F. Sandoval-Ibarra, "Implementation of SoC Based Real-Time Electromagnetic Transient Simulator," Mathematical Problems in Engineering, vol. 2017, Article ID 5274517, 2017.

[42] S. Ji, F. Xiao, and D. Tan, "Analytical method for softness abrasive flow field based on discrete phase model," Science China Technological Sciences, vol. 53, no. 10, pp. 2867-2877, 2010. 
[43] D.-P. Tan, P.-Y. Li, Y.-X. Ji, D.-H. Wen, and C. Li, "SA-ANNbased slag carry-over detection method and the embedded WME platform," IEEE Transactions on Industrial Electronics, vol. 60, no. 10, pp. 4702-4713, 2013.

[44] N. Zheng, M. Jin, H. Hong, L. Huang, Z. Gu, and H. Li, "Realtime and precise insect flight control system based on virtual reality," IEEE Electronics Letters, vol. 53, no. 6, pp. 387-389, 2017.

[45] Z. Wu, N. Zheng, S. Zhang, X. Zheng, L. Gao, and L. Su, "Maze learning by a hybrid brain-computer system," Scientific Reports, vol. 6 , no. 1, 2016. 


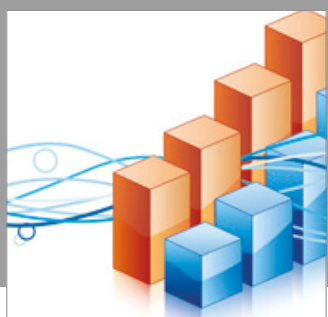

Advances in

Operations Research

vatersals

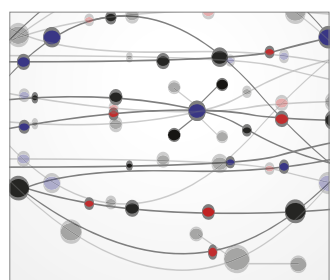

\section{The Scientific} World Journal
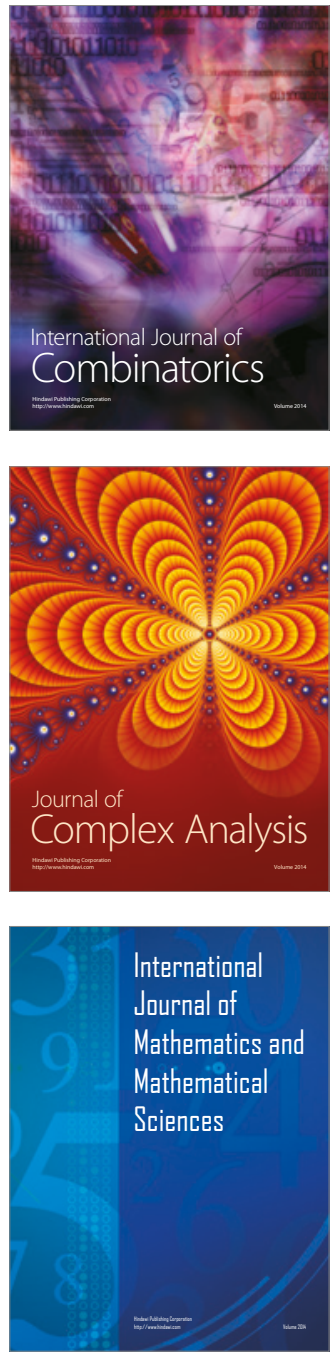
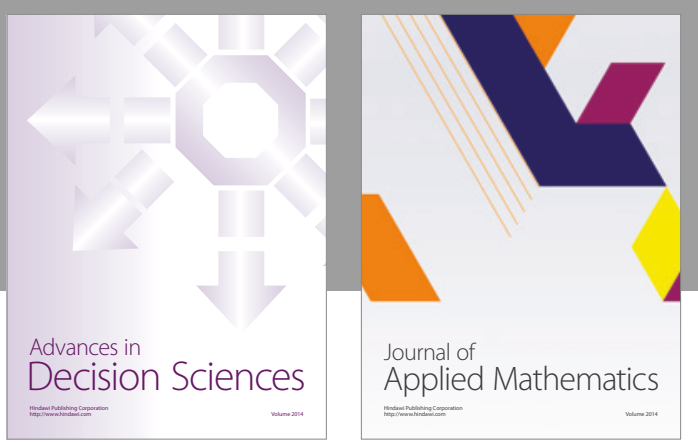

Algebra

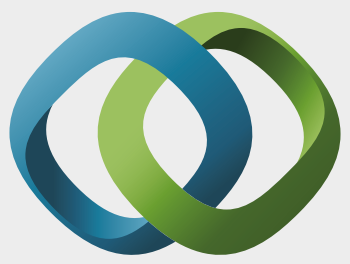

\section{Hindawi}

Submit your manuscripts at

https://www.hindawi.com
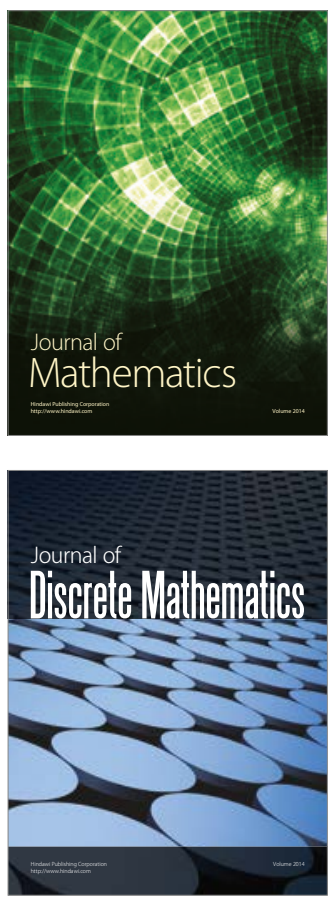

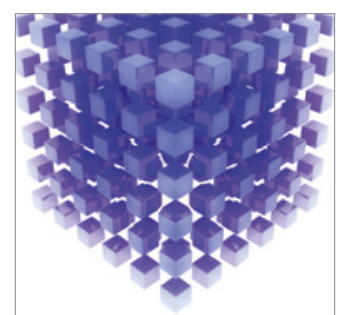

Mathematical Problems in Engineering
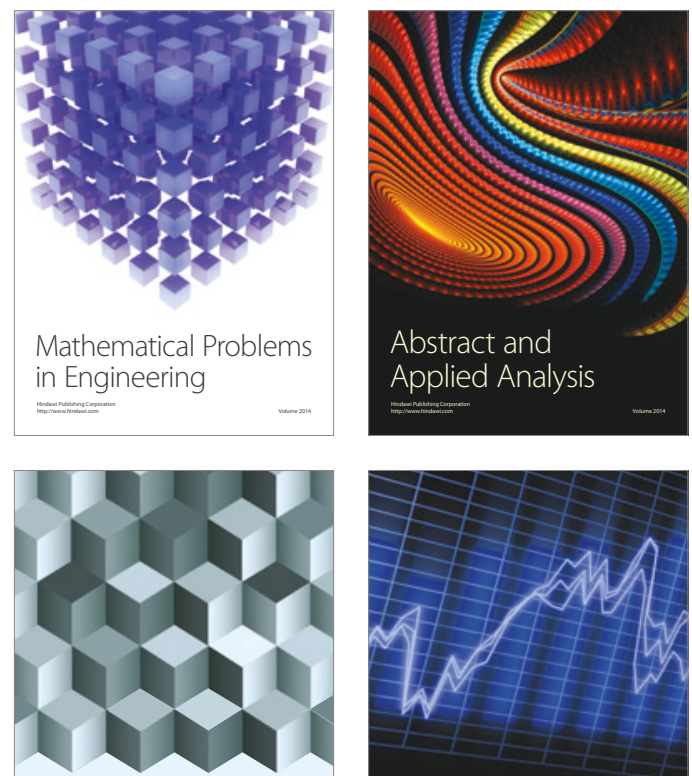

Journal of

Function Spaces

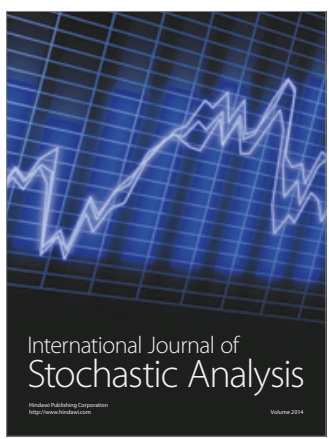

Probability and Statistics
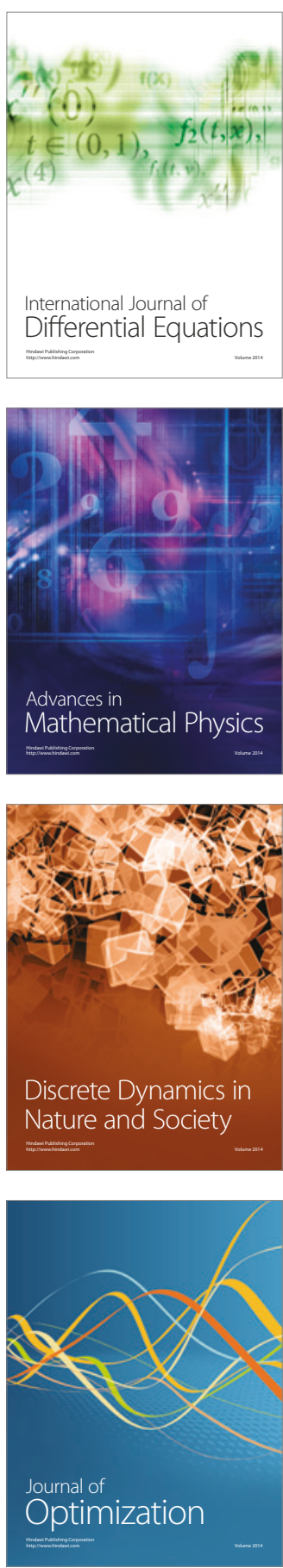